University of Tennessee Health Science Center UTHSC Digital Commons

$12-2012$

\title{
The Health of Rural Grandparents Raising Grandchildren
}

Kimberly Y. Robitaille

University of Tennessee Health Science Center

Follow this and additional works at: https://dc.uthsc.edu/dissertations

Part of the Other Mental and Social Health Commons

\section{Recommended Citation}

Robitaille, Kimberly Y. , "The Health of Rural Grandparents Raising Grandchildren" (2012). Theses and Dissertations (ETD). Paper 229. http://dx.doi.org/10.21007/etd.cghs.2012.0264.

This Dissertation is brought to you for free and open access by the College of Graduate Health Sciences at UTHSC Digital Commons. It has been accepted for inclusion in Theses and Dissertations (ETD) by an authorized administrator of UTHSC Digital Commons. For more information, please contact jwelch30@uthsc.edu. 


\title{
The Health of Rural Grandparents Raising Grandchildren
}

\begin{abstract}
Introduction: Grandparents are becoming increasingly responsible for raising their grandchildren. Previous studies have noted physical and mental health limitations for custodial grandparents. Grandparents face numerous challenges in raising grandchildren and consequently, experience high stress levels. However, coping and social support have been found to mediate grandparent stress. Rural custodial grandparents have been an understudied population. Using the Stress Process Model, this study extends the knowledge of rural grandparents raising grandchildren by describing the relationships among physical and mental health, stressors, coping, and social supports for custodial grandparents living in Western Kentucky.
\end{abstract}

Methods: A mixed methods approach was used to examine the physical and mental health, stress, coping, and social support of 21 custodial grandparents residing in rural Western Kentucky. The participants completed questionnaires as measures of physical and mental health, stress, coping, and social support. In addition, two focus groups were conducted to obtain the grandparents' perceptions of the effects stressors, coping, and social supports have on their physical and mental health. SAS 9.2 was used for all quantitative data analyses and NVivo9 was used for thematic content analysis of all qualitative data.

Results: Rural custodial grandparents in this study had a mean age of 59.8 years and most had one grandchild living with them. Most were Caucasian, married, and unemployed. The participants were found to have below average physical health and low average mental health. Rural grandparent stress levels were in the normal range and they preferred coping strategies that promoted personal growth, problem solving, and controlling their emotions. They had low levels of social support. Five themes emerged from the qualitative analysis which included "Physical health isn't a problem," "Mental Health: I need me time," "Stress, that's the problem," "Coping: I just have to talk to someone," and "Informal supports: a necessity." Finally, the quantitative and qualitative results were integrated for an in-depth description of this sample.

Discussion/Conclusion: While custodial grandparents in this study had below average physical health, they did not perceive that to be a concern. Mental health for the sample was average but participants reported periodic depression and required personal time to manage their mental health. They perceived stress to be their main problem but not from parenting, child behavior, or parent-child interactions.

Grandparents in this study had three preferred coping strategies. However, no associations were found between their preferred coping strategies and their health. Grandparents discussed having someone to talk to as being paramount. The findings of this study contribute a deeper understanding of custodial grandparent health and support the use of the Stress Process Model with rural grandparents.

\section{Document Type}

Dissertation

Degree Name

Doctor of Philosophy (PhD)

\section{Program}

Nursing

\section{Research Advisor}

Mona N. Wicks, PhD, RN, FAAN 


\section{Keywords}

Caregiving, Coping, Grandparents, Health, Mixed Methods, Stress

\section{Subject Categories}

Medicine and Health Sciences | Mental and Social Health | Other Mental and Social Health 
The Health of Rural Grandparents Raising Grandchildren

\author{
A Dissertation \\ Presented for \\ The Graduate Studies Council \\ The University of Tennessee \\ Health Science Center
}

\author{
In Partial Fulfillment \\ Of the Requirements for the Degree \\ Doctor of Philosophy \\ From The University of Tennessee
}

By

Kimberly Y. Robitaille

December 2012 
Copyright (C) 2012 by Kimberly Y. Robitaille. All rights reserved. 


\section{DEDICATION}

To my family:

My husband Tim for his unyielding support and encouragement.

My daughter Tiffany for her understanding, willing ear, and inspiration.

My son Daniel for thinking I'm going to be an "Über" nurse.

My mom and dad for bragging about me to everyone they meet. 


\section{ACKNOWLEDGEMENTS}

I would like to thank Dr. Margaret Hartig, Dr. Elizabeth Tolley, and Ms. Belinda Hardy for their time and guidance while serving on my dissertation committee.

I would also like to thank Dr. J. Carolyn Graff, dissertation committee member, for providing me with opportunities that increased my knowledge of research methodology and qualitative research. She has graciously given her time and expertise to support me while completing my doctorate and this has been invaluable to my success.

Finally, I would like to thank Dr. Mona Wicks, dissertation committee chair and advisor. She has been fundamental to my success. Words cannot express the gratitude I have for her enthusiastic support, positive attitude, constant encouragement, and expertise. She $i$ s the nurse scientist I will strive to become. 


\begin{abstract}
Introduction: Grandparents are becoming increasingly responsible for raising their grandchildren. Previous studies have noted physical and mental health limitations for custodial grandparents. Grandparents face numerous challenges in raising grandchildren and consequently, experience high stress levels. However, coping and social support have been found to mediate grandparent stress. Rural custodial grandparents have been an understudied population. Using the Stress Process Model, this study extends the knowledge of rural grandparents raising grandchildren by describing the relationships among physical and mental health, stressors, coping, and social supports for custodial grandparents living in Western Kentucky.

Methods: A mixed methods approach was used to examine the physical and mental health, stress, coping, and social support of 21 custodial grandparents residing in rural Western Kentucky. The participants completed questionnaires as measures of physical and mental health, stress, coping, and social support. In addition, two focus groups were conducted to obtain the grandparents' perceptions of the effects stressors, coping, and social supports have on their physical and mental health. SAS 9.2 was used for all quantitative data analyses and NVivo9 was used for thematic content analysis of all qualitative data.
\end{abstract}

Results: Rural custodial grandparents in this study had a mean age of 59.8 years and most had one grandchild living with them. Most were Caucasian, married, and unemployed. The participants were found to have below average physical health and low average mental health. Rural grandparent stress levels were in the normal range and they preferred coping strategies that promoted personal growth, problem solving, and controlling their emotions. They had low levels of social support. Five themes emerged from the qualitative analysis which included "Physical health isn't a problem," "Mental Health: I need me time," "Stress, that's the problem," "Coping: I just have to talk to someone," and "Informal supports: a necessity." Finally, the quantitative and qualitative results were integrated for an in-depth description of this sample.

Discussion/Conclusion: While custodial grandparents in this study had below average physical health, they did not perceive that to be a concern. Mental health for the sample was average but participants reported periodic depression and required personal time to manage their mental health. They perceived stress to be their main problem but not from parenting, child behavior, or parent-child interactions. Grandparents in this study had three preferred coping strategies. However, no associations were found between their preferred coping strategies and their health. Grandparents discussed having someone to talk to as being paramount. The findings of this study contribute a deeper understanding of custodial grandparent health and support the use of the Stress Process Model with rural grandparents. 


\section{TABLE OF CONTENTS}

CHAPTER 1. INTRODUCTION ..................................................................................

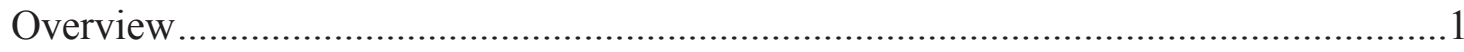

Purpose of the Study ......................................................................................... 1

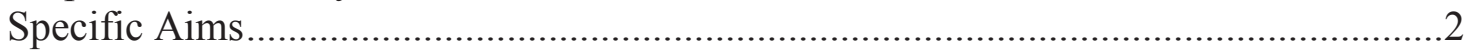

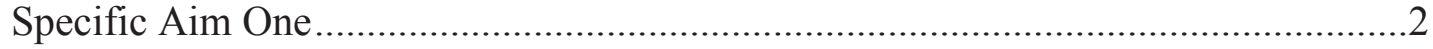

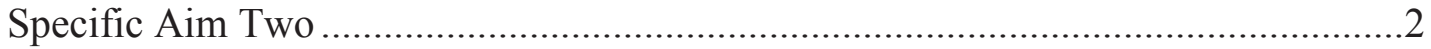

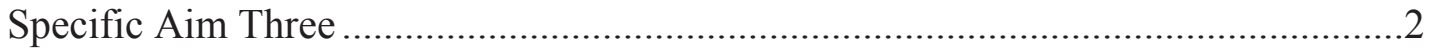

Specific Aim Four .........................................................................................

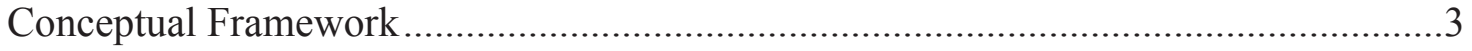

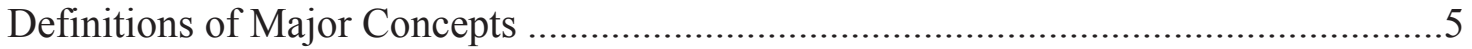

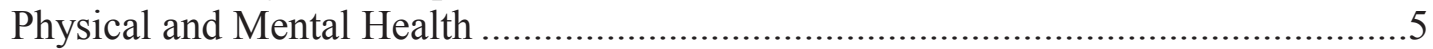

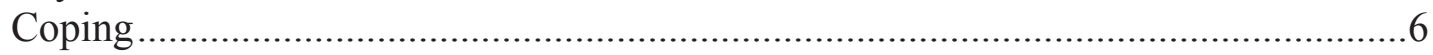

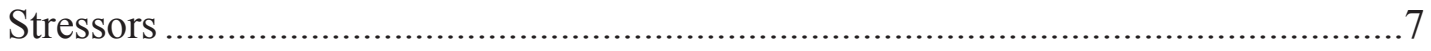

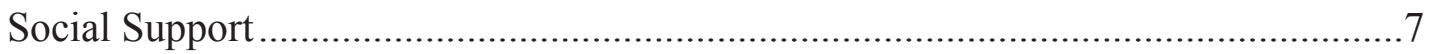

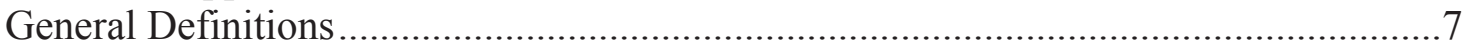

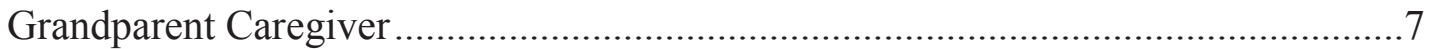

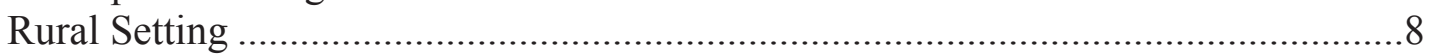

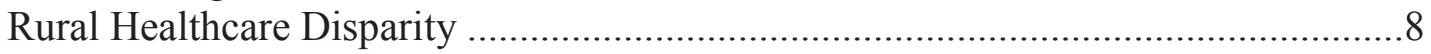

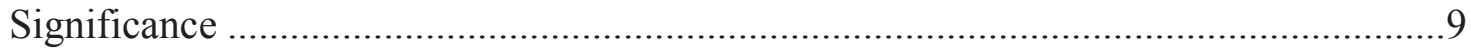

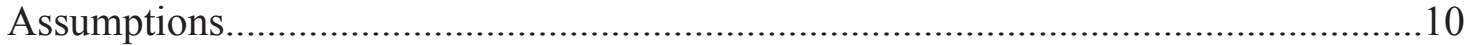

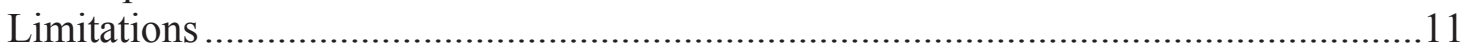

CHAPTER 2. REVIEW OF LITERATURE .........................................................13

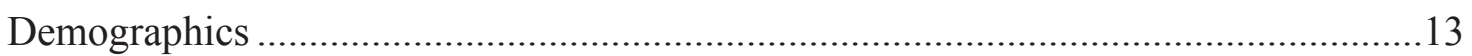

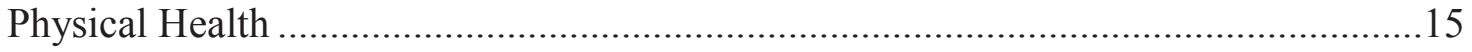

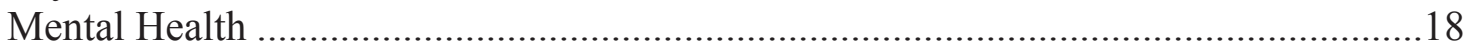

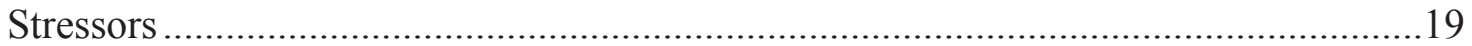

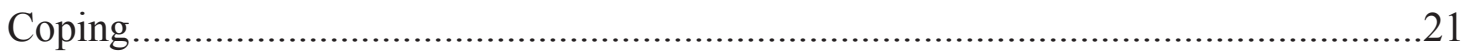

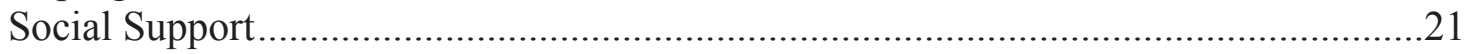

CHAPTER 3. METHODOLOGY .............................................................................23

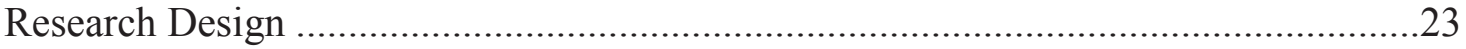

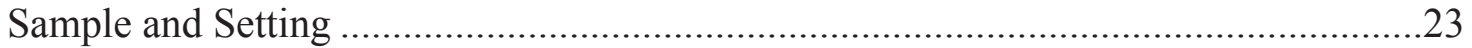

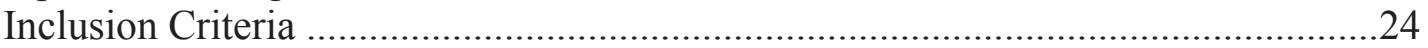

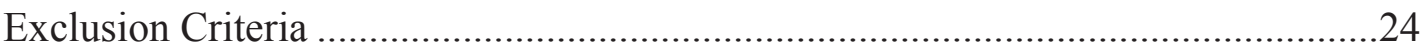

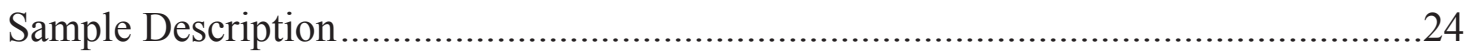

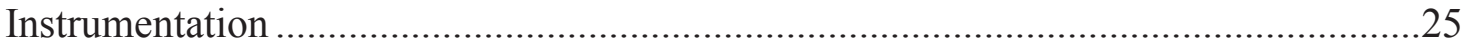

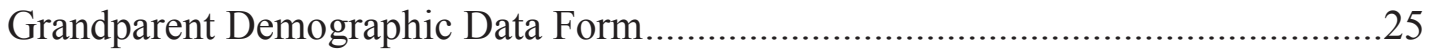

Short Form-36 General Health Survey ...............................................................25

Center for Epidemiologic Studies for Depression Scale........................................26

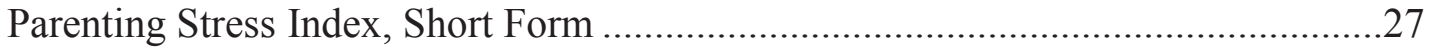

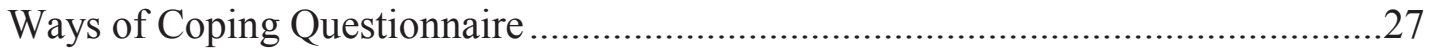

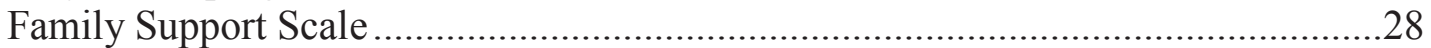




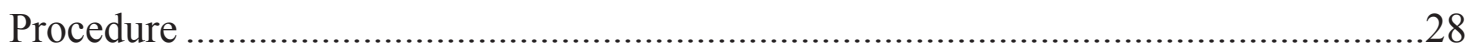

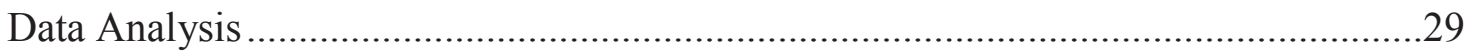

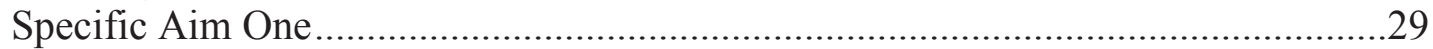

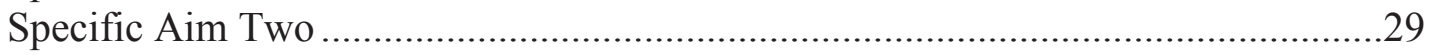

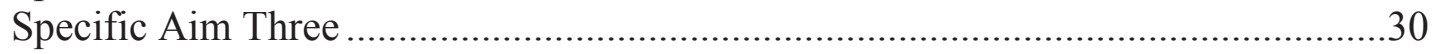

Specific Aim Four .......................................................................................

Consideration of Human Subjects ……………………............................................30

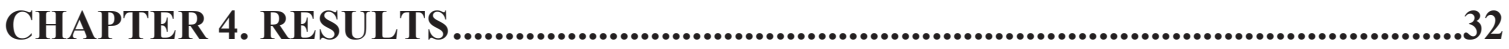

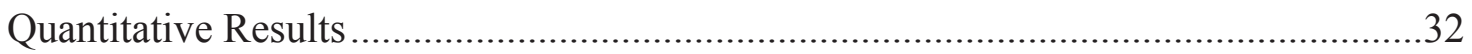

Rural-dwelling Custodial Grandparent Characteristics ..........................................32

Physical and Mental Health, Stressors, Coping, and Social Support Scores ..............36

Relationships among Health, Stressors, Coping, and Social Support.........................42

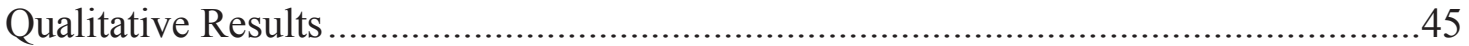

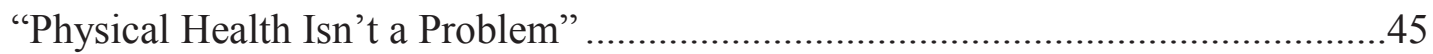

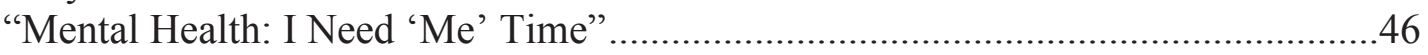

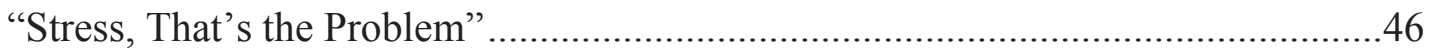

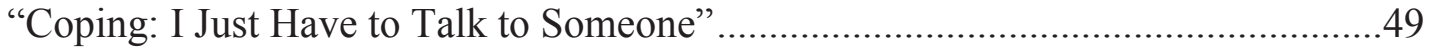

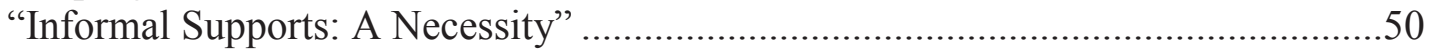

Quantitative and Qualitative Integration.................................................................52

CHAPTER 5. DISCUSSION AND IMPLICATIONS...............................................56

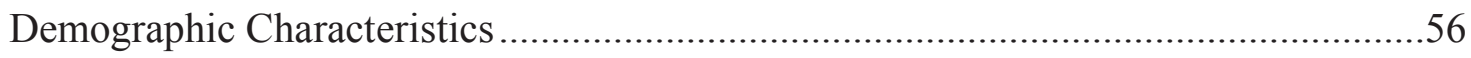

Physical and Mental Health, Stressors, Coping, and Social Support ...........................57

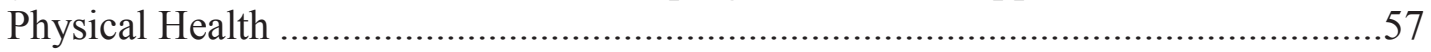

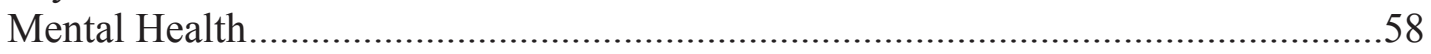

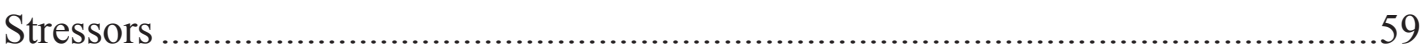

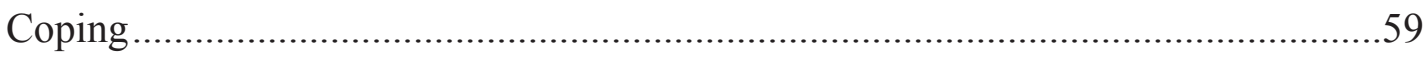

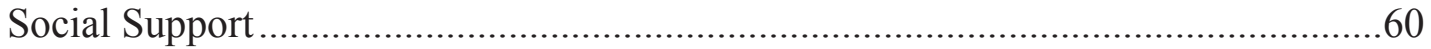

Relationships among Health, Stressors, Coping, and Social Support ...........................60

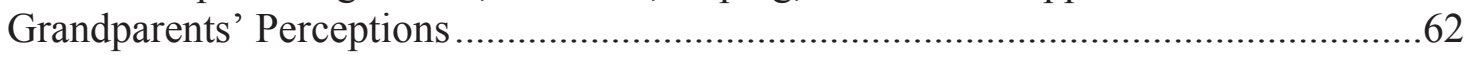

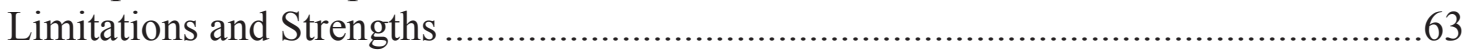

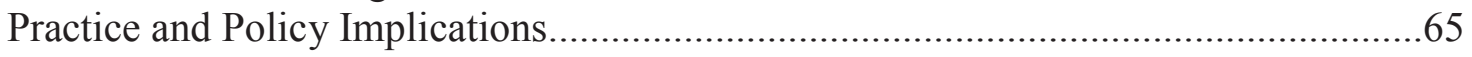

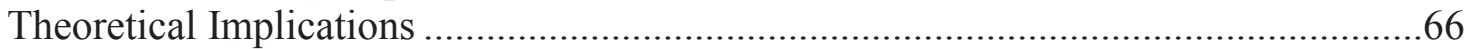

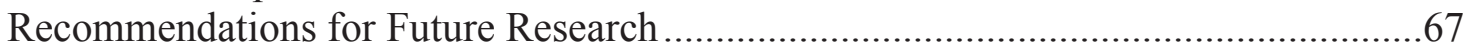

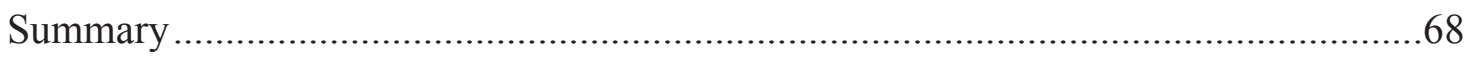

LIST OF REFERENCES .................................................................................................69

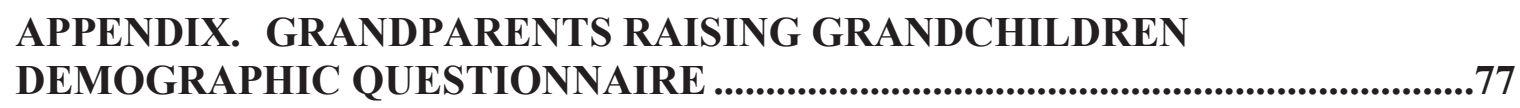

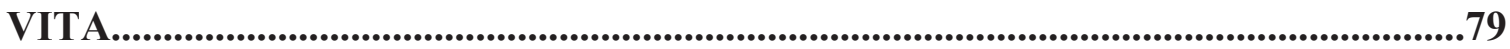




\section{LIST OF TABLES}

Table 4-1. Demographic Characteristics of a Sample of Rural-dwelling Custodial Grandparents Raising Grandchildren in Western Kentucky $(\mathrm{N}=21)$....

Table 4-2. Types of Insurance Reported by a Sample of Rural-dwelling Custodial Grandparents Raising Grandchildren in Western Kentucky $(\mathrm{N}=21)$

Table 4-3. Current Medical Problems Reported by a Sample of Rural-dwelling Custodial Grandparents Raising Grandchildren in Western Kentucky $(\mathrm{N}=21)$

Table 4-4. Reasons for Custody of Grandchildren Reported by a Sample of Ruraldwelling Custodial Grandparents Raising Grandchildren in Western Kentucky $(\mathrm{N}=21)$

Table 4-5. Description of Self-reported Physical and Mental Health, Stress, Coping, and Social Support for a Sample of Rural-dwelling Custodial

Grandparents Raising Grandchildren in Western Kentucky $(\mathrm{N}=21)$

Table 4-6. Comparisons of Self-reported Physical Health and Coping Strategies for Rural-dwelling Custodial Grandparents Raising Grandchildren in Western Kentucky Based on Employment Status.

Table 4-7. Comparisons of Self-reported Coping Strategies and Social Support for Rural-dwelling Custodial Grandparents Raising Grandchildren in Western Kentucky Based on Marital Status.

Table 4-8. Effect of Number of Children on Self-reported Mental Health for Ruraldwelling Custodial Grandparents Raising Grandchildren in Western Kentucky

Table 4-9. Relationships among Physical and Mental Health, Stressors, Coping, and Social Support for Rural-dwelling Custodial Grandparents Raising Grandchildren in Western Kentucky $(d f=24)$

Table 4-10. Integration of Quantitative and Qualitative Data Analysis Results for Rural-dwelling Grandparents Raising Grandchildren in Western Kentucky 


\section{CHAPTER 1. INTRODUCTION}

\section{Overview}

There is widespread belief that elders feel younger and happier when children are nearby. However, raising one's grandchildren represents a much different situation than visiting with grandchildren for brief periods. According to the 2010 United States Census, there are 2.7 million grandparents responsible for the basic needs of one or more grandchildren living with them (U. S. Census Bureau, n. d.). There has been an increase in the number of grandchildren living in grandparent-headed households during the past decade (Goyer, 2010; Johnson \& Kasarda, 2011). Of this population, 63\% are grandmothers as head of household and $21.2 \%$ have incomes below the poverty level (U. S. Census Bureau, n. d.). Custodial grandparents have the added stress of the financial responsibility for their grandchildren. Hayslip and Kaminski (2005) found that custodial grandparents raising grandchildren do not receive the social or financial support necessary for this task. These authors also found that custodial grandparents have a higher incidence of stress, depression, diabetes, hypertension, and insomnia compared to noncustodial grandparents (Hayslip \& Kaminski, 2005). In some of these studies (Kelley, Whitley, Sipe, \& Yorker, 2000; Musil, 1998, 2000) investigators have focused solely on grandmothers as they are the most frequent caregivers (U. S. Census Bureau, 2008).

While many research studies document the challenges of raising grandchildren, little is known about custodial grandparents raising grandchildren in rural settings or about how this responsibility affects their health (Hayslip \& Kaminski, 2005). In general, rural residents have less access to healthcare and are more likely to be older and poor; to have fair or poor health; and to have chronic health problems compared to urban residents (Agency for Healthcare Research and Quality [AHRQ], 2008). They also are likely more isolated in their experience as a grandparent raising grandchildren as they are farther removed from their neighbors when compared to urban custodial grandparents. All of these factors could combine to have a negative impact on the custodial grandparent's health.

\section{Purpose of the Study}

The purpose of this study was to examine the physical and mental health, stress, coping, and social support of rural custodial grandparents residing in Kentucky. When grandparents are faced with raising their grandchildren, they must adapt to being in the caregiver role again. This process draws on the grandparents' past experiences, personal characteristics, and shared history with their grandchild. This adaptation may be overwhelming to many grandparents as they may have little time to prepare themselves for this role. In addition, grandparents will need to adapt to changes in lifestyle, social activities, and physical exertion necessitated by having custody of their grandchild. These changes can increase stress, which affects several dimensions of caregiver health 
including self-reported health, health symptoms, illness, and medication use (Son et al., 2007). The current study examined the influence of stress, coping, social supports, and caring for grandchildren on rural-dwelling grandparents' physical and mental health.

\section{Specific Aims}

The specific aims of this study intended to a) provide a description of ruraldwelling grandparents raising their grandchildren; b) examine the relationship between physical and mental health, stress, coping, and social supports for the grandparents; and c) determine the perceived effect the responsibility for the grandchildren's welfare has on grandparents' health. The variables used in this study have been described in the grandparent raising grandchildren literature.

\section{Specific Aim One}

Describe the demographic characteristics (i.e. age, gender, race, marital status, socioeconomic status, number of grandchildren in home, age and gender of grandchildren in home, length of time with grandchildren in home, reason for custody, and classification of residential area) of rural-dwelling custodial grandparents. Along with the demographic characteristics, grandparents were asked to report any medical conditions or health problems, insurance status and type, and availability of healthcare services.

\section{Specific Aim Two}

Describe the physical and mental health status, stressors, coping, and social support of rural-dwelling custodial grandparents.

\section{Specific Aim Three}

Examine the relationships among physical and mental health status, stressors, coping, and social support of rural-dwelling custodial grandparents.

\section{Specific Aim Four}

Explore grandparents' perceptions of the effects stressors, coping, and social support have on their physical and mental health status. 


\section{Conceptual Framework}

The conceptual framework utilized for this study is the caregiver Stress Process Model developed by Pearlin, Mullan, Semple, and Skaff (1990). The Stress Process Model provides an understanding of how caregiving, as a dominant component of an interpersonal relationship, exerts a stressful impact on the caregiver; the Stress Process Model also explores the possible outcomes of this stress (Pearlin et al., 1990). The stress process, as illustrated in Figure 1-1, includes the four domains of a) background and context, b) stressors, c) mediators of stress, and d) outcomes of stress (Pearlin et al., 1990). The variables for this study of rural-dwelling custodial grandparents mirror the four domains of the Stress Process Model. Therefore, this study tested the interrelatedness among the four domains of the Stress Process Model for rural-dwelling custodial grandparents by examining the relationships of demographic characteristics (background and context), stressors (primary and secondary), mediators (coping, social supports), and physical and mental health (outcomes).

The Stress Process Model demonstrates the interrelatedness of multiple factors in increasing, as well as decreasing, the stress of caregiving. The background and context of the stress process include key characteristics of the individual, such as age, ethnicity, and caregiving history, that can influence his or her response to stress (Pearlin et al., 1990). Stressors are the second domain of the Stress Process Model, which are divided into primary and secondary stressors. Primary stressors are conditions that are problematic for the caregiver, such as dependency of the care recipient, behavioral problems, and relationship changes (Pearlin et al., 1990). Secondary stressors are the result of the primary stressors and are further divided into role strains and intrapsychic strains. However, this characterization of stressors does not indicate that secondary stressors are less important than primary stressors; rather the two types of stressors are interrelated and emerge as the stress process unfolds (Pearlin et al., 1990). Coping and social support are considered to be the primary mediators for handling stress and allow some caregivers to manage better than others (Pearlin et al., 1990). Mediators can decrease the intensity of the stressors as well as block the cascade of secondary stressor development (Pearlin et al., 1990). Finally, outcomes are the effects of caregiving on the individual. Pearlin et al. (1990), believe that the emotional effects are seen first then lead to a physical health decline, which could eventually result in a surrender of caregiving.

Stressors have been associated with an increase in depressive symptoms among grandmother caregivers (Leder, Nicholson Grinstead, \& Torres, 2007). Stress has also been shown to have a negative effect on physical health for caregivers by elevating levels of stress hormones (Vitaliano, Young, \& Zhang, 2004). Increased levels of stress hormones contribute to hyperglycemia, hyperinsulinemia, hypertension, and poorer immune functioning (Vitaliano et al., 2004). Chronic stress is associated with sleep problems, risky health behaviors, and illness progression of existing disease (Vitaliano et al., 2004).

Resources, such as coping skills and social supports, are predictive of better health and investigators have found improvement in grandmothers' physical abilities and 


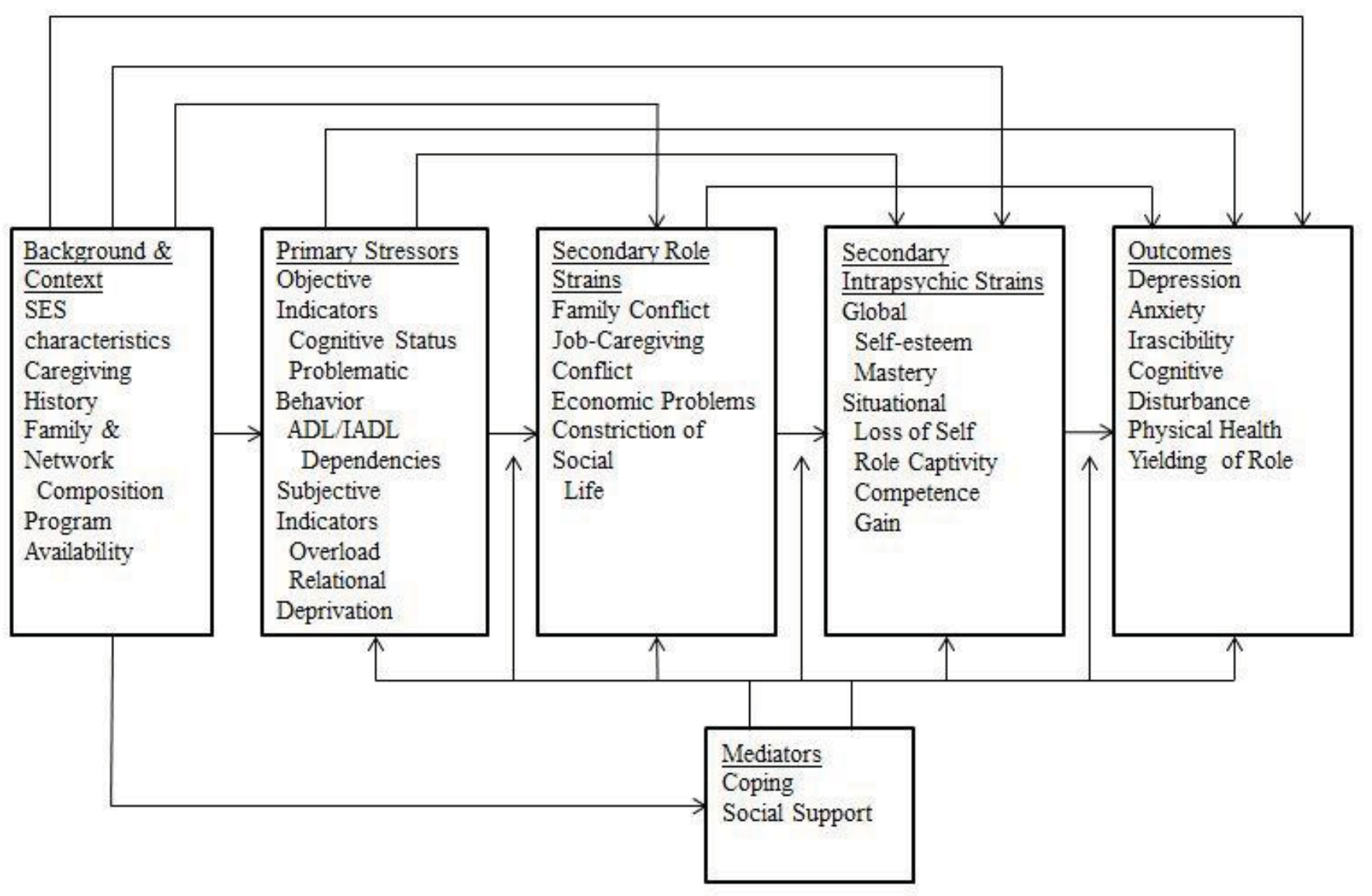

\section{Figure 1-1. The Stress Process Model}

Note. Reprinted with permission. Pearlin, L. I., Mullan, J. T., Semple, S. J., \& Skaff, M. M. (1990). Caregiving and the stress process: An overview of concepts and their measures. The Gerontologist, 30(5), 583-594. 
mental health when resources are utilized (Musil, Warner, Zauszniewski, Wykle, \& Standing, 2009; Vitaliano et al., 2004). However, coping skills, such as unhealthy eating, smoking, and alcohol use, may promote a decline in physical and mental health. Physical and mental health for the grandparent raising grandchildren may depend on the use of positive mediators to achieve the best health outcome possible.

\section{Definitions of Major Concepts}

There are many definitions available in the literature for the variables explored in this study. The following concepts and definitions were used for physical and mental health, coping, stressors, and social supports.

\section{Physical and Mental Health}

Since the time of Hippocrates, philosophers and scientists have tried to define health and the parameters that constitute health (Larson, 1999). The World Health Organization (WHO) proposed a definition in 1948, that health requires a person to have complete physical, mental, and social wellbeing as well as the absence of disease (Larson, 1999; Saylor, 2004). However, this definition is limited and does not reflect the complexity of human beings or acknowledge the advances that have been made in healthcare. Nurse theorists have provided several alternative definitions of health but there is lack of consensus and a universal definition of health remains elusive.

For this study, the theoretical definition of health is that of King. King (1990) defined health as a dynamic state over the life of an individual where the individual adjusts to environmental stressors through use of resources to achieve daily living potential. Grandparents may have existing health problems, many of which may be chronic conditions. In the context of King's definition, if the grandparent uses resources available to manage their disease and remain as functional and independent as possible, he or she is a healthy person. For the purposes of this study, health is viewed as a subjective phenomenon and was determined by asking grandparents to rate their own health and the frequency with which physical and emotional limitations affected their ability to perform their usual activities.

In the Stress Process Model, both physical and mental health are viewed as outcomes of the stress process. During the development of the Stress Process Model, Pearlin et al. (1990) included standard symptom measures of depression, anxiety, irascibility, and cognitive disruptions in the construct of mental health. In developing the physical health component of the Stress Process Model, caregivers were asked about their physical health, limitations in their ability to perform usual activities, and the occurrence of injuries (Pearlin et al., 1990). In the model, physical and mental health declines result in a surrender of the caregiver role unless there is the influence of mediators to lessen the effects of the stress (Pearlin et al., 1990). However, physical and mental health may be influenced by the mix of circumstances, experiences, responses, and resources. This mix 
is not stable for a given caregiver, and a change in one component of the Stress Process Model can result in changes of the other components (Pearlin et al., 1990).

For this study, the operational definition of physical and mental health is defined by the Short Form-36, version 2 General Health Survey (SF36v2) score and the Center for Epidemiologic Studies for Depression (CES-D) score. The SF36v2 was used to measure physical and mental health in this study. The developers of the SF36 noted that the patient is the best judge of achieving medical care goals that preserve functioning and well-being and therefore developed a self-report questionnaire (Ware \& Sherbourne, 1992). A grandparent was considered healthy if their score on the SF36v2 was higher than 50 on a range of $0-100$, with healthier persons achieving higher scores (Leder et al., 2007). The CES-D was used to measure mental health also. This instrument is based on self-report for the major components of depressive symptomatology as these items are subjective and can only be assessed by the individual (Radloff, 1977). If the grandparent should score 16 or higher on the CES-D, that score would indicate a risk for clinical depression (Musil et al., 2009).

\section{Coping}

Coping is a person's ability to manage or alter the source of stress and regulate the emotional response to that stress (Shaw, 1999), which is the theoretical definition utilized by this study. Research has shown that maladaptive coping can have negative effects on physical and emotional health and people who used maladaptive coping strategies were more likely to become ill during the year following the stressful event (Shaw, 1999). The multiple problems faced by custodial grandparents require effective coping skills. The effectiveness of custodial grandparent coping is dependent on the resources available and learned coping techniques. Grandparents must cope with the changes in their roles, difficult relationships, and possibly grief over the loss of their child or spouse (Hayslip \& Kaminski, 2005).

For this study, coping is operationally defined by the use of the Ways of Coping Questionnaire (WCQ). The authors of the WCQ define coping as "the cognitive and behavioral efforts made to master, tolerate, or reduce external and internal demands and conflicts among them" (Folkman \& Lazarus, 1980, p. 223), which is consistent with the theoretical definition used by this study. A higher score on a subscale of the WCQ indicates frequent use of that coping strategy (Trail Ross \& Aday, 2006). The Ways of Coping Questionnaire measures coping processes, not coping styles or dispositions (Folkman \& Lazarus, n.d.). Folkman and Lazarus (1980) define coping processes as "what the person actually thinks and does in a particular encounter and to changes in these efforts as the encounter unfolds" (p. 224). 


\section{Stressors}

Standard definitions of stress only include the negative aspects of stress so a definition that reaches consensus remains elusive (American Institute of Stress, n. d.). Stress is the personal reaction to having little or no control over a life situation and stressors are the events in life that cause stress (American Institute of Stress, n. d.). The stressors that grandparents face are numerous and include financial responsibility for the grandchildren, few or no institutional supports (Hughes, Waite, LaPierre, \& Luo, 2007), health and behavior issues for the grandchildren (Musil et al., 2009), and chronic conflicts with the grandchildren's parents (Leder et al., 2007). In this study, stress is operationally defined using the Parenting Stress Index Short Form (PSI/SF). The author of the PSI/SF developed this instrument with the assumption that stressors are additive and multidimensional affecting the parent-child relationship (Abidin, 1995). In this study, the custodial grandparent has assumed the parent role and develops the same type of relationship with the child. The PSI/SF items focus on three aspects of the parentchild relationship, which include parental distress, parent-child interactions, and difficult child. These three aspects correspond to the primary stressors, some of the secondary role strains (i.e. family conflict and constriction of social life), and all of the secondary intrapsychic strains of the Stress Process Model. Persons with total stress scores at or above the $90^{\text {th }}$ percentile are experiencing clinically significant levels of stress (Abidin, 1995).

\section{Social Support}

Investigators hypothesize that there are two types of social support that can help a person cope: main effects and buffering (Shaw, 1999). The main effect hypothesis states that people with stronger social support will have better health regardless of the stressors present (Shaw, 1999). The buffering hypothesis purports that people with stronger social support will have better health during exposure to stressors (Shaw, 1999). Social support then is the forming of interpersonal relationships and obtaining information that alters a person's assessment of the stress symptoms and the ability to cope with the symptoms (Shaw, 1999). For this study, social support is operationally defined by the use of the Family Support Scale which measures the helpfulness of social support for families with young children (Dunst, Trivette, \& Jenkins, 2007). Higher scores on this instrument indicate higher levels of social support (Kelley et al., 2000).

\section{General Definitions}

\section{Grandparent Caregiver}

Descriptions are found in the literature of three different types of grandparent caregivers. One type of grandparent provides nonresident care (babysitting) for at least one grandchild of 50 hours or more per year (Hughes et al., 2007). A second type of 
grandparent cares for grandchildren in a multigenerational home where the grandparent lives with at least one adult child and one or more grandchildren (Hughes et al., 2007). This type of grandparent caregiver is also called a co-parenting grandparent. The third type of grandparent, called a custodial grandparent, lives with one or more grandchildren with no adult child present (Hughes et al., 2007). Custodial grandparents care for their grandchildren on a full-time basis and have financial responsibility for the grandchildren (Grinstead, Leder, Jensen, \& Bond, 2003). In the current study, the focus is on the health of custodial grandparents who reside in a rural setting.

\section{Rural Setting}

What are the attributes that make an area rural? There are many definitions of rural in the literature but no consensus has been reached. United States Government Agencies, such as the U. S. Census Bureau and Office of Management and Budget (OMB), use different definitions depending on the needs of their program (Spencer, Cromartie, Hart, \& Hirsch, 2010). Research suggests that a single definition of rural is not possible or needed and the selected definition should fit the task at hand (Racher, Vollman, \& Annis, 2004). This study focuses on grandparents living in the Pennyrile region of Western Kentucky. The Pennyrile region includes nine counties: Caldwell, Christian, Crittenden, Hopkins, Livingston, Lyon, Muhlenberg, Todd, and Trigg. According to the Economic Research Service (ERS) of the U. S. Department of Agriculture (2007), the counties of Western Kentucky are primarily considered rural areas. This determination of rural status is based on nine representative definitions of rural from the U. S. Census Bureau, OMB and ERS (Economic Research Service of the U. S. Department of Agriculture, 2007).

The Pennyrile region of Kentucky is primarily a farming community with manufacturing, coal mining, tourism, construction, healthcare services, and retail services supporting the economy of the area (Kentucky State Data Center, n. d.). The population of the largest city in the Pennyrile region is 27,415 (U. S. Census Bureau, 2010) and it is at least an hour-long drive to an urban area with a population over 100,000. The principle investigator for this study lives in one of the Pennyrile region counties and knows the residents of the region consider it to be rural. To define the rural setting for this study, a question was added to the demographic questionnaire asking participants to classify their area of residence as rural, suburban, or urban.

\section{Rural Healthcare Disparity}

Rural healthcare disparities have been well documented in numerous publications; for example, the Agency for Healthcare Research and Quality produces an annual report on healthcare disparities in the U. S. with the 2009 report being the most recent (Spencer, 2010). In this report, rural healthcare disparities continue to exist as rural residents are more likely to have fair to poor health, chronic conditions, limited healthcare access, and must travel longer distances for healthcare than their urban counterparts (Agency for 
Healthcare Research and Quality [AHRQ], 2009). Since rural healthcare disparities exist, grandparents raising their grandchildren in rural settings are likely to have greater unmet health needs than those living in urban or suburban communities.

Health disparities and healthcare disparities are terms that are used frequently in the literature as interchangeable terms (Fink, 2009). Fink (2009) suggests that these terms are different and that a definition of either term has not been agreed upon in the literature. She conducted a concept analysis of these terms and has proposed definitions for both concepts (Fink, 2009). However, the concept that best fits this study is healthcare disparity and the theoretical and operational definitions proposed by Fink were used for this study. The theoretical definition proposed by Fink (2009) for healthcare disparity is "inequity in access to health services or difference in quality of health services received for one individual or group compared to another that is not a result of individual or group variance" (p. 355). The operational definition proposed by Fink (2009) for healthcare disparity is a "difference in a measurement of access to or quality of health care services between an individual or group possessing a defined characteristic when other variables have been controlled, such as individual health choices, disease courses, and other variation from the normative measure (p. 355)." Since healthcare disparity is documented in the literature (Agency for Healthcare Research and Quality [AHRQ], 2009; Fink, 2009), this study used these definitions to describe existing healthcare disparities for grandparents raising grandchildren in a rural setting.

\section{Significance}

According to the 2010 American Community Survey one-year estimates (U. S. Census Bureau, n. d.), there are seven million grandparents who have their grandchildren living with them and $64.1 \%$ of these grandparents are grandmothers. These statistics demonstrate an increase in grandparent caregivers when compared to the $2000 \mathrm{U}$. S. Census report of 6.1 million grandparents with grandchildren living with them (U. S. Census Bureau, 2008). Most grandparents (50\%) are under 60 years of age and live in the southern United States (48\%; (Simmons \& Dye, 2003)). In Kentucky, 108,000 children live in grandparent-headed households (Grandfactsheets.org, n. d.). There are no data available on the number of children or grandparents living in rural Kentucky. However, $72 \%$ of the grandparents in Kentucky are under the age of 60 and 25\% live in poverty (Grandfactsheets.org, n. d.).

Studies conducted concerning the health of grandparents raising grandchildren support a decline in their physical and mental health and increased stress, depression, and limited social support (Grinstead et al., 2003; Hayslip \& Kaminski, 2005). However, these studies have been limited to grandparents living in urban areas. Rural residents have fewer healthcare resources and are more likely to be older, poor, in fair to poor health, and have more chronic health problems when compared to urban residents (Agency for Healthcare Research and Quality [AHRQ], 2008). These health disparities, along with fewer social supports and longer distances to travel for services, place the rural grandparent raising grandchildren at increased risk for a decline in their physical 
and mental health. Information is needed about custodial grandparents living in a rural setting so that future interventions are tailored to their needs and not based on the descriptions of urban grandparents. Research on rural custodial grandparents may also provide the basis for comparison of urban versus rural custodial grandparent health so that variables contributing to any health differences can be identified. Grandparent studies have included caregivers who were Caucasian, African American, and Latino grandparents (Hughes et al., 2007; Musil, 1998) or have focused on a specific ethnic group, either African American or Latino (Burnette, 1999; Kelley et al., 2000). In Kentucky, $87 \%$ of custodial grandparents are White with African American and Hispanic/Latino comprising 10\% and 1\%, respectively (Grandfactsheets.org, n. d.).

The major reasons for grandparents raising their grandchildren are parent death, incarceration, mental illness, substance abuse, and/or neglect/abuse of the children (Grinstead et al., 2003). There is also the possibility that a custodial child will have special needs, such as a child born to a mother using illicit drugs during pregnancy. A child with special needs would increase the stress and demands placed on the grandparent. Grandparents are seen in society as a "safety valve" that can be used to care for children during times of family crisis (Cox, 2000). Additionally, there may be no one else to assume care of the children. When grandparents assume care of grandchildren, society views the situation as "nonnormative", which can leave grandparents feeling confused, isolated, resentful, and unsure of their role (Cox, 2000; Hughes et al., 2007). However, some subgroups may view the situation as "normative".

When grandparents assume this new role, their stress level increases, coping skills are challenged, and their health is affected (Hayslip \& Kaminski, 2005). If the grandparent's health deteriorates so that they are unable to care for the grandchildren, the grandchildren will be placed in the foster system. Placement in foster care causes trauma for children as they experience separation and loss of a safe, caring, and stable family (Johns, 2000). Children in foster care for extended periods experience foster care drift as they are moved to different foster families and do not form attachment to family or a sense of belonging to anyone (Johns, 2000). This problem was recognized as early as 1959 and legislation has been passed requiring permanency planning in the child welfare system as a strategy to preserve the family for the benefit of the children (Johns, 2000). According to Johns (2000), placement with the grandparent allows grandchildren to "remain connected to their existing personal support network, community, and cultural background" (p. 161). Finally, utilizing grandparents to raise grandchildren conserves public resources and eliminates the debate over public responsibility for the children (Hughes et al., 2007). As this is a continuing societal problem, this research study will attempt to further the knowledge of grandparent health by focusing on custodial grandparents raising grandchildren in a rural setting.

\section{Assumptions}

The following assumptions influenced the formulation of this research study's conceptual framework, design, and interpretation of findings: 
1. Grandparents are aware of their health history and are able to self-report their physical and mental health using the health instruments selected for this study.

2. Stress is assumed to occur when a rural grandparent becomes responsible for raising grandchildren.

3. Concepts within the study's conceptual framework are relevant to rural grandparents raising grandchildren.

4. The instruments in this study have demonstrated validity and reliability in previous grandparent raising grandchildren research.

5. Grandparents take responsibility for raising their grandchildren because they are concerned about the welfare of the children.

\section{Limitations}

The following limitations were identified for this study:

1. Since this is a cross-sectional design, it may not provide adequate representation of grandparents raising grandchildren in a rural setting as the results may be misleading or ambiguous for inferences over time (Polit \& Beck, 2008).

2. Grandparents may respond with answers that are socially desirable. They may not provide honest answers or acknowledge poor health for fear that it may affect their status as a caregiver for their grandchildren. However, providing questionnaires for data collection provides anonymity (Polit \& Beck, 2008).

3. The CES-D is a self-assessment screening tool for depression and is not diagnostic of depression. However, scores on this instrument reflect perceived depressive symptoms and are not an indicator of mental health.

4. Grandparents with severe depression may not be represented as they may not volunteer for participation in this study.

5. This study will use convenience sampling to recruit participants, which could limit the generalizability of the study's findings (Polit \& Beck, 2008). An additional limitation to the generalizability of the findings is restricting participant recruitment to nine counties in Western Kentucky. However, as this is a descriptive study and information on grandparents raising their grandchildren in a rural setting is limited, convenience sampling is an appropriate method. 
6. Recruiting an adequate sample size for this study from the grandparent raising grandchildren population in Western Kentucky may be difficult. If this is not feasible, then the area of recruitment will be expanded in Kentucky to include other surrounding rural counties until a sufficient sample size is reached.

7. Mistrust of the researcher as an outsider may limit successful recruitment of rural grandparents.

8. Study instruments have not been used with rural grandparents in previous research. 


\section{CHAPTER 2. REVIEW OF LITERATURE}

Since late 1980s, the health of grandparents raising their grandchildren has been a research concern. The earliest studies described the grandparent population while the most recent studies have included interventions to improve custodial grandparent health. Several variables have been identified in the literature such as physical and mental health, stress, coping, and social supports. Each of these variables was measured in the current study along with a description of situational variables such as marital status and reasons for custody of the grandchildren. This chapter will include a synthesis of these research studies, specifically focusing on the aforementioned variables and the impact they have on custodial grandparent health.

\section{Demographics}

Early caregiving grandparent research focused on describing this population's characteristics and prevalence. Characteristics of this population include a description of race (African American, Caucasian, Hispanic/Latino, American Indian, and Alaskan Native), age range from 30 s to 80 s, and predominately female (Fuller-Thomson \& Minkler, 2005; Hayslip \& Kaminski, 2005; Kelley, Whitley, \& Campos, 2010; Musil et al., 2009; Trail Ross \& Aday, 2006). While a few researchers have focused on African American custodial grandparents, the majority have included a mixture of races in their samples. For this study, participants were recruited regardless of race because of the inability to predict racial percentages of custodial grandparents within the Pennyrile Area with any certainty. Age of the caregiver is important since most custodial grandparents assume responsibility for their grandchildren when there is a potential for declining health related to complex factors such as age, additive effects of negative health behaviors, and genetic predisposition.

The impact of income on custodial grandparent health has been examined. Grandparents assume financial responsibility for their grandchildren with minimal, if any, financial assistance and may have to quit working to care for the grandchildren (Gerard, Landry-Meyer, \& Roe, 2006; Grinstead et al., 2003; Kelley et al., 2000). Many grandparents raising their grandchildren live at the poverty level (Baker \& Silverstein, 2008; Dowdell, 2004; Fuller-Thomson \& Minkler, 2000; Goodman \& Silverstein, 2002; Kelley et al., 2010; Kropf \& Robinson, 2004; Roe, Minkler, Saunders, \& Thomson, 1996; U. S. Census Bureau, 2008), although higher levels of income do not mitigate the stress grandparents can experience when raising a grandchild (Trail Ross \& Aday, 2006). Race and socioeconomic status can overlap to increase the risk for grandparent health problems as minorities are more likely to be impoverished and live in communities with few resources (Hughes et al., 2007).

A situational variable that has been included in studies of grandparents raising grandchildren is caregiver status (Fuller-Thomson \& Minkler, 2000; Goodman \& Silverstein, 2002; Hughes et al., 2007). These studies have made comparisons between 
co-parenting and noncustodial grandparents to explore the health effects based on level of caregiving. Custodial grandparents are defined as grandparents who assume the parental role and care for the grandchildren in absence of the birth parent (Fuller-Thomson \& Minkler, 2000; Goodman \& Silverstein, 2002). Co-parenting grandparents live in the house with the grandchildren and the birth parent (Goodman \& Silverstein, 2002). Noncustodial grandparents do not live with the grandchildren but have periodic contact with them (Fuller-Thomson \& Minkler, 2000). According to Fuller-Thomson and Minkler (2000), African American custodial grandparents $(\mathrm{N}=78)$ have poorer physical health and increased incidence of depression compared to African American noncustodial grandparents $(\mathrm{N}=495)$. However, another study, with a larger sample $(\mathrm{N}=12,872)$ of mixed race, compared grandparents by caregiving type and found limited evidence of this outcome when the researchers controlled for caregiving context and circumstances (Hughes et al., 2007). In addition to sample size differences, the opposing findings of these two studies may be related to variations in the statistical techniques used that controlled for or did not control for confounding variables. When custodial and coparenting grandparents are compared, there is little difference in the level of stress and well-being they report (Goodman \& Silverstein, 2002).

In some studies, marital status is a factor that has been predictive of worse physical and mental health in grandparent caregivers (Blustein, Chan, \& Guanais, 2004; Dowdell, 2005). Custodial grandparents who are unmarried are more likely to report poorer health (Dowdell, 2005), depressive symptomatology (Blustein et al., 2004) and stress (Musil, Youngblut, Ahn, \& Curry, 2002) than their married counterparts. Other situational variables included in custodial grandparent studies are the effects of relationships with the birth parents and grandchildren, change in the grandparents' roles, and the reasons they have custody (Butler \& Zakari, 2005; Dellman-Jenkins, Blankemeyer, \& Olesh, 2002; Goodman \& Silverstein, 2002; Grinstead et al., 2003; Hayslip \& Kaminski, 2005; Linsk et al., 2009; Musil et al., 2009; Trail Ross \& Aday, 2006). In some qualitative studies, a difficult relationship with an adult child has been identified as a source of major stress for custodial grandparents (Bullock, 2004; Burton, 1992; Kropf \& Kolomer, 2004; Kropf \& Robinson, 2004; Waldrop \& Weber, 2001).

There has been little research on grandparents residing in rural locations specifically. Myers, Kropf, and Robinson (2002) wrote one of the first articles exploring the needs of rural grandparents. These authors suggested guidelines for implementing a case management intervention to support these grandparents. This approach was designed to promote the use of the custodial grandparents' strengths and available resources while raising their grandchildren (Myers et al., 2002). Kropf and Robinson (2004) conducted a qualitative study with 14 grandparents that explored the reasons rural grandparents became responsible for their grandchildren. The authors identified three major pathways to custodianship that included co-residential, incremental, and immediate situations and how these pathways affected the grandparents (Kropf \& Robinson, 2004). However, this study did not focus on health specifically.

Most recently, a study was conducted comparing the health of rural and urban grandparents (Bigbee, Musil, \& Kenski, 2011). In this study the authors compared rural 
and urban grandparent health, categorizing caregivers as primary, multigenerational, and traditional caregivers. Primary grandparents were defined as having responsibility for their grandchildren without the children's parents living in the home. Multigenerational grandparents were defined as co-residing with the children and the children's parents. Finally, traditional grandparents were defined as living within one hour of their grandchildren, being in contact with their grandchildren, and providing less than 20 hours of care for the grandchildren per week. This study compared these rural-urban groups in terms of demographic characteristics, physical and mental health scores, and reported health conditions using the General Health Survey, Short-form 36 and the Centers for Epidemiological Studies Depression Scale. Bigbee, Musil, et al. found that the grandparents were similar in employment, age, and educational level. However, some differences were noted as well such as racial distribution with the majority of rural grandparents being white $(89.7 \%)$ compared to the urban grandparents $(59.6 \%)$. Another difference was the distribution of caregiver type with fewer rural grandparents living in multigenerational homes and more classified as traditional grandparents than the urban grandparents (Bigbee, Musil, et al., 2011). In summary, these studies suggest that most grandparent caregivers have numerous financial stressors and several situational variables such as caregiver status, marital status, and difficult parent-adult child relationships that form the context for their role as custodial grandparents. Limitations of these studies include small, unrepresentative samples and use of diverse statistical analysis techniques that make synthesis across studies difficult. Strengths include definitions of grandparents by caregiving type, descriptions of caregiving grandparents' characteristics and insight into the situational variables that form the context of caring for grandchildren. The physical and mental health findings will be discussed in the next section of this document.

\section{Physical Health}

Physical health has been a concern in most of the studies conducted on grandparent health. Most researchers have found that grandparents raising grandchildren experience a negative impact on their physical health (Bigbee, Boegh, Prengaman, \& Shaklee, 2011; Butler \& Zakari, 2005; Fuller-Thomson \& Minkler, 2000; Minkler \& Fuller-Thomson, 1999; Musil, 1998). However, other investigators have noted improved physical health due to increased activity, weight loss, and smoking cessation after taking on the caregiver role (Minkler, Roe, \& Price, 1992; Roe et al., 1996). These mixed results demonstrate the complexity of the factors influencing physical health status for grandparents raising grandchildren. Kelley, Whitley, and Campos (2010) noted that the lack of multi-dimensional, standardized measures of grandparent health was a limitation in this area of science. Some previous studies included a single question for obtaining the grandparents' self-assessed health status (Musil \& Ahmad, 2002; Roe et al., 1996), which may not provide an accurate picture as grandparents tend to downplay their own health problems to protect the grandchildren (Minkler et al., 1992). Bullock (2004) also noted that grandmothers tended to minimize their own health and social needs when caring for an unhealthy child instead putting their own health concerns aside to provide a better situation for the child. An example of this pattern was described in a study of 71 
grandmothers. Several grandmothers in the study reported not taking prescription medications so they could be alert when caring for the grandchildren (Minkler et al., 1992).

Overall, most studies on grandparent caregivers' health indicate that physical health and functional limitations are common. Musil (1998) found that $(\mathrm{N}=90)$ caring for multiple grandchildren resulted in lower self-reported health and increased stress. In a study of 173 primary caregiving grandparents, Minkler and Fuller-Thomson (1999) compared their activity limitations and self-rated health to 3304 non-caregiving grandparents and found custodial grandparents were significantly more likely to report activity limitations and a lower satisfaction with their health than non-caregiving grandparents. Likewise, Whitley, Kelley, and Sipe (2001) found at least moderate levels of physical limitation negatively impacting the completion of normal daily routines in a sample of 100 African American custodial grandparents. Butler and Zakari (2005) conducted a mixed methods study of 17 custodial grandparents in which 35\% reported worse health than five years previously and approximately $50 \%$ reported their current health limited their activities. A link has also been noted between psychological distress and physical health (Kelley et al., 2000). In a study of 102 custodial grandparents, Kelley et al. (2000) found that grandparents who had few resources, less social support, and poor physical health reported higher levels of psychological distress. In a study of 26 grandfathers aged 65+, Bullock (2007) reported similar results, that those with poorer physical health reported more powerlessness when compared to grandfathers reporting better physical health. Research findings such as these have prompted researchers to develop interventions aimed at empowering and educating custodial grandparents to improve their health.

Intervention studies for custodial grandparents have included home-based intervention programs that promote physical and mental health with the aim of improving coping and reducing stress levels (Kelley, Whitley, \& Sipe, 2007). One of the first programs implemented by Kelley et al. (2007) provided social work and nursing services for one year to 120 custodial grandmothers. Social workers visited the home twice monthly to focus on identifying and using personal, familial, and community strengths that would help grandparents reach their goals and resolve problems. A registered nurse $(\mathrm{RN})$ visited the home monthly and provided ongoing health assessment with education on health concerns and medications. The participants also attended support group meetings and parent education classes as part of the program. Data were collected preand post-test and the researchers found statistically significant improvements in mental health. However, no statistically significant effect was noted for physical health after the intervention, even though post-test scores for physical health were slightly elevated. This lack of significant improvement in physical health could be related to fit of the intervention to the physical health measure. The researchers used the SF36 Physical Functioning Scale as a measure of physical health. This scale measures a person's ability to perform activities such as kneeling, vigorous activity, walking, climbing stairs, and carrying groceries (Ware, 2000). However, the intervention provided for physical health was health screening (measures of blood pressure, weight, cholesterol, and blood glucose), medication checks, monitoring of health needs, referrals to healthcare 
providers, and health education. Therefore, while these interventions are important, they do not address any activity limitations of the study participants. The inclusion of an intervention to more closely match the measurement criteria could be a recommendation for future intervention studies.

Another intervention study conducted by Kelley et al. (2010) included 529 custodial grandmothers in a longitudinal, pretest-posttest design. Very similar to their 2007 study, the intervention included home visits by RNs and social workers, support group meetings, and parenting classes (Kelley et al., 2010). Nursing services included a) an initial health assessment (body mass index measurement, visual acuity, glucose and cholesterol blood levels, and blood pressure); b) a health behaviors assessment (current diagnosis of diabetes, hypertension, obesity, and use of tobacco, alcohol, and seat belts); c) medication check; d) health education; e) healthcare provider referral; and f) development of goals for health. The study participants also received glucometers and blood pressure monitoring equipment. The nurse continued to monitor blood pressure, weight, medications, diet, and physical activity during the subsequent home visits. For this study, the participants completed the SF36 General Health Survey pre- and post-test and comparisons were made for the instrument's eight scales. Only four of the SF36 scales were significantly different after the intervention and included role functioning: physical, vitality, role functioning: emotional, and mental health (Kelley et al., 2010). According to Kelley et al. (2010), "there were no significant differences in mean scores for physical functioning, bodily pain, general health, and social functioning” (p. 383). While each of the SF36 scales' raw scores did show some improvement, as with the authors' 2007 intervention study, the health interventions did not appear to fit with the measures of physical functioning, bodily pain, general health, and social functioning. The authors also indicated that more longitudinal intervention studies are needed in the future to determine if the changes can be sustained.

Rural grandparents have recently become a research interest. A study comparing the health of 97 rural and 388 urban custodial grandparents found no significant differences (Bigbee, Musil, et al., 2011). However, both groups were below the adult norm for their SF36 physical and mental health composite scores, with the physical health composite score being the lower of the two. A second recent study focused on an intervention for frontier custodial grandparents (Bigbee, Boegh, et al., 2011). In this study of 11 frontier custodial grandparents, a 6-month home based program was implemented to provide health education, behavior change reinforcement, and connection with resources. On the initial home visit, the participants completed the HealthPromoting Lifestyle Profile II and SF36 general health surveys pre- and post-intervention as well as other health screenings (body mass index, lipids, blood glucose, blood pressure, and a health history). After the initial home visit, the intervention included monthly nursing visits to provide education and reinforcement of health goals.

According to Bigbee, Boegh, et al. (2011), "pre-intervention findings suggested that these grandparents had significant physical health concerns, particularly obesity, hypertension, and diabetes" (p. 158). In this study, investigators reported that grandparent health was unchanged after the intervention (Bigbee, Boegh, et al., 2011), although they did note a statistically significant improvement in diastolic blood pressure and nutrition. There are 
some limitations with this study. The authors only reported the SF36 physical component summary and mental health component summary measures pre- and post-test. This does not allow the reader to determine if the intervention was ineffective in improving the participants' health or if the lack of significant health improvement was due to a poor fit of the intervention to the measure. Another limitation noted by the authors was the lack of consistency in applying the intervention to the different participants, except to note that everyone received the main elements of education and reinforcement. Information was not provided about the differences in providing the intervention to the participants, which leaves the reader unable to evaluate the treatment fidelity. A final limitation noted by the study authors was the small sample size of six frontier families.

While some research has shown poorer physical health in custodial grandparents, some researchers have reported positive health gains (Roe et al., 1996; Waldrop \& Weber, 2001). Roe et al. (1996) attribute improving physical and mental health to possibilities such as grandparent empowerment in a situation where they were once powerless and the daily influence of a young child in their life. Some grandparents demonstrate improved physical health which they attribute to decreasing or quitting smoking, losing weight, eating healthier, and increasing activity (Minkler et al., 1992; Waldrop \& Weber, 2001). However, in the study by Minkler et al. (1992) and Waldrop and Weber (2001), this finding was only in $25 \%$ and $11 \%$ of the study samples respectively. These findings suggest that custodial grandparent health is greatly influenced by the contextual issues in which they are raising their grandchildren.

\section{Mental Health}

Mental health is of great concern for custodial grandparents since most grandparent health research has noted increased depressive symptomatology among custodial grandparents (Bigbee, Musil, et al., 2011; Blustein et al., 2004; Bullock, 2004; Burton, 1992; Butler \& Zakari, 2005; Fuller-Thomson \& Minkler, 2000; Kelley et al., 2000; Linsk et al., 2009; Minkler, Fuller-Thomson, Miller, \& Driver, 1997; Minkler et al., 1992; Musil, 1998, 2000; Musil \& Ahmad, 2002; Roe et al., 1996; Ruiz, Zhu, \& Crowther, 2003; Waldrop \& Weber, 2001). In a study of 60 custodial grandparents, $86 \%$ reported feeling depressed or anxious most of the time (Burton, 1992). Minkler et al. (1992) reported similar findings in a study of African American grandmothers $(\mathrm{N}=71)$ where the majority of grandparents reported feeling depressed, couldn't get going, totally exhausted, or lonely. In this mixed methods exploratory study, the researchers used an abbreviated version of Blackburn's Affective Balance Scale to gather information about the grandparent's emotional status as well as self-rated health questions directed at physical and mental health. According to the authors, Blackburn's Affective Balance Scale elicits self-reported data on feelings experienced in the past week such as feeling appreciated, totally exhausted, and depressed. These data were gathered during two participant interviews and means were presented for the various self-report items as well as qualitative data obtained during the interviews. Previous research findings indicate that caregiving grandparents are up to twice as likely to have depressive symptoms when compared to non-caregiving grandparents (Fuller-Thomson \& Minkler, 2000; Minkler et 
al., 1997). However, some researchers have not found a high degree of depressive symptomatology in caregiving grandparents (Whitley et al., 2001). In this study of 100 urban African American custodial grandmothers, mental health was measured using the Short Form-36 General Health Survey and the Health Risk Appraisal. The Health Risk Appraisal includes a self-assessment element on life satisfaction. The mental health findings of this study may reflect an inconsistent use of instruments to measure depressive symptomatology in grandparents raising grandchildren research and a lack of contextual data on the study population's caregiving situation.

Certain contextual circumstances may be correlated with increased depressive symptomatology in custodial grandparents. Musil et al. (2009) conducted a study to examine the moderating effects of resourcefulness and social support on family stress, strain, and depressive symptoms for a group of grandmothers by caregiver type. This study included 183 custodial, 136 multigenerational, and 167 non-caregiver grandmothers. According to this study, greater intra-family strain and low instrumental support contributed to increased depressive symptoms (Musil et al., 2009). However, it is uncertain whether the depression symptoms existed before caregiving began or developed afterward (Hughes et al., 2007; Musil et al., 2009; Musil et al., 2002). Baker and Silverstein (2008) conducted a study comparing grandparents who had recently stopped caring for a grandchild, had recently begun caring for a grandchild, had been continuously caring for a grandchild or were non-caregiving grandparents. The findings of this study included high levels of depression before caregiving began and increased levels of depression when the grandchildren transitioned in or out of grandparent care when compared to continuous care or non-caregiving grandparents (Baker \& Silverstein, 2008). Other contextual circumstances contributing to increased depressive symptomatology in custodial grandparents include a) having two or more illnesses; b) history of grandparent emotional problems; c) caregiving of multiple grandchildren; d) caring for teenage grandchildren (Linsk et al., 2009); e) being a recent custodial grandparent (Minkler et al., 1997); f) poorer self-rated physical health (Bullock, 2007; Kelley et al., 2000); g) being unmarried (Blustein et al., 2004); and h) grandchildren's behavior problems (Leder et al., 2007).

\section{Stressors}

Custodial grandparents face many stressors when raising grandchildren such as financial concerns (Bullock, 2004; Dowdell, 2005; Kelley et al., 2000; Waldrop \& Weber, 2001), custody and legal issues (Kropf \& Kolomer, 2004; Waldrop \& Weber, 2001), emotional or behavioral problems of the children (Kropf \& Kolomer, 2004; Leder et al., 2007), and their relationship with the children's parents (Bullock, 2004; Leder et al., 2007; Waldrop \& Weber, 2001). Many researchers have described a high degree of stress for most custodial grandparents and the health effects of the stress (Baker \& Silverstein, 2008; Bullock, 2004; Burton, 1992; Butler \& Zakari, 2005; Dowdell, 2004; Kelley et al., 2000; Kropf \& Kolomer, 2004; Leder et al., 2007; Musil, 1998; Musil \& Ahmad, 2002; Musil et al., 2009; Musil et al., 2002; Trail Ross \& Aday, 2006; Waldrop $\&$ Weber, 2001). In a study of 50 custodial grandparents, $92 \%$ scored greater than the 
$90^{\text {th }}$ percentile on the Parenting Stress Index, which indicates significant stress levels (Trail Ross \& Aday, 2006). However, other researchers have not reported stress levels as high in custodial grandparents but they were still noteworthy (Butler \& Zakari, 2005; Kelley, 1993; Musil, 1998). Several researchers have found that increased stress for custodial grandparents has the most impact on their mental health (Leder et al., 2007; Musil et al., 2009).

The length of caregiving time for the custodial grandparent has been linked to increased stress (Baker \& Silverstein, 2008). In a study comparing grandparents who obtained custody of grandchildren within the past two years to non-caregiving grandparents, the new custodial grandparents were found to have a lower level of wellbeing and increased stress levels (Baker \& Silverstein, 2008). Increased levels of stress are noted when grandparents are suddenly thrust into the caregiver role causing a tremendous upheaval in their lives (Leder et al., 2007; Musil et al., 2002). Family relationships and conflict are reported by custodial grandparents to be the most frequent stressor (Burton, 1992; Kropf \& Kolomer, 2004; Waldrop \& Weber, 2001). Custodial grandparents may be navigating difficult relationships with adult children with drugaddiction or mental health disorders. This stressful situation can be further compounded if the custodial grandparent does not have legal custody as they fear the child may be returned to an unfit parent or the parent appears demanding return of the child (Bullock, 2004; Gerard et al., 2006; Kropf \& Kolomer, 2004; Waldrop \& Weber, 2001). Custodial grandparents must also cope with the grandchildren's feelings of abandonment and anger toward their parent as well as any psychiatric or physical health problems the children may have as a result of abuse/neglect or substance abuse exposure (Kropf \& Kolomer, 2004; Leder et al., 2007).

Financial strain is another significant contributor to stress for the custodial grandparent (Bullock, 2004; Dowdell, 2005; Waldrop \& Weber, 2001). Custodial grandparents frequently receive little assistance in caring for a grandchild (Bullock, 2004), either because they are unaware of how to navigate the social services system, lack custody status (Gerard et al., 2006), or a reluctance to accept "welfare" assistance. According to a qualitative study by Bullock (2004), "They [custodial grandparents] attempted to manage the child's health needs with out-of-pocket payments. This management strategy often forced grandparents to choose between a health maintenance visit for the grandchild, purchasing their own medications, or buying food for the family. According to these families, the most necessary expense was food, which would benefit everyone. However, the sacrifice of health care for food cost for the entire family placed both grandchild and grandparents at further risk for illness (p. 50)." In a study of 102 custodial grandparents, Kelley et al. (2000) noted the contribution of financial strains on the psychological distress experienced by custodial grandparents which in turn, impacted their mental health. As this illustrates, stress for the custodial grandparent occurs for numerous reasons and will require myriad coping skills to mediate the effect stress has on their physical and mental health. 


\section{Coping}

Coping behaviors are how people respond to stressful life events and they can be positive or maladaptive strategies affecting health. Since many custodial grandparents experience a great deal of stress with raising grandchildren, how they cope with stress has been an integral component in custodial grandparent health research (Bullock, 2004, 2007; Burton, 1992; Gerard et al., 2006; Kelley et al., 2007; Minkler et al., 1992; Musil, 1998, 2000; Musil \& Ahmad, 2002; Trail Ross \& Aday, 2006; Waldrop \& Weber, 2001). In a study of 50 custodial grandparents by Trail Ross and Aday (2006), custodial grandparents "tended to use social support and positive attitudes as the major ways of coping with their situation" (p. 923). Using the Ways of Coping Questionnaire, the authors found "five coping strategies were significantly correlated to lower reported stress: positive reappraisal, accepting responsibility, confrontive coping, self-control, and distancing. These coping strategies were very positive techniques for handling stress" ( $\mathrm{p}$. 928; Trail Ross \& Aday, 2006). Trail Ross and Aday (2006) also noted the most frequent coping mechanisms used by grandparents was social support and positive attitudes. Musil and Ahmad (2002) found that grandparents who "used more active coping strategies, which is a more problem-focused approach, and less avoidant coping also reported better health" (p. 116).

Several positive coping mechanisms were identified by Waldrop and Weber (2001) that included taking action, talking about feelings, spiritual faith, working more, focusing on child, and outreach to others. The use of religion and spirituality as a coping mechanism has been described as an important coping mechanism in other custodial grandparent studies (Bullock, 2004, 2007). However, maladaptive coping strategies have been identified in custodial grandparent research as well. These strategies include smoking, increased alcohol and coffee consumption, overeating, and staying up too late (Burton, 1992; Minkler et al., 1992; Waldrop \& Weber, 2001). A qualitative study by Minkler et al. (1992) described a 62-year-old grandmother with diabetes who had missed four medical appointments in the previous year because of caregiving responsibilities or confusion in her home. These situations highlight how coping strategies can result in either a positive or a negative effect on custodial grandparent health.

\section{Social Support}

Social support is another component of grandparent raising grandchildren research. Its presence can be a benefit in mitigating stress (Bullock, 2007; Dowdell, 2004; Hughes et al., 2007; Kelley et al., 2007; Leder et al., 2007; Musil et al., 2009; Trail Ross \& Aday, 2006) or, if not available or utilized, the lack of social support can be a source of stress and depression (Butler \& Zakari, 2005; Hughes et al., 2007; Kelley et al., 2000; Musil et al., 2009). Custodial grandparents have little or no time when they are able to socialize with family or friends leaving them isolated in their experience (Bullock, 2004; Butler \& Zakari, 2005; Whitley et al., 2001). Various types of informal and formal social support have been identified as beneficial for custodial grandparents. 
Some of the formal social supports identified as protective against stress by Trail Ross and Aday (2006) included professional counseling, tutoring, and special education. Support groups are one social support that appears to have a tremendous impact on coping and stress for custodial grandparents (Dowdell, 2004). The majority (88\%) of custodial grandparents, in a study by Leder et al. (2007), gained emotional support and felt less isolation when they attended support groups. In this study, the authors found a significant relationship between improved physical health and social support; though none of the mental health scales were related to social support. Monthly support groups provided a venue for custodial grandparents to exchange ideas, develop a support network, and recognize their own strengths, abilities, self-worth, and the positive factors in their lives (Kelley et al., 2007). Finally, spirituality is an additional social support used by custodial grandparents to cope with stress and bolster their well-being (Bigbee, Boegh, et al., 2011; Bullock, 2007; Butler \& Zakari, 2005). Social supports for custodial grandparents are important mediators in the stress process as they prevent the development of secondary stressors, such as constriction of social life, poor self-esteem, and loss of self, ultimately improving the caregiving experience for custodial grandparents. 


\section{CHAPTER 3. METHODOLOGY}

This chapter discusses the research design used for this study. The sample is described including the inclusion/exclusion criteria and study setting. This chapter provides information on the instruments used for data collection and their applicability to the study population. Finally, the procedure for conducting the study is outlined to include Institutional Review Board (IRB) approval for the study, selection of participants, data analysis techniques, and protection of human subjects.

\section{Research Design}

This cross-sectional, descriptive, correlational study used a mixed methods approach to examine the physical and mental health, stress, coping, and social support of 21 custodial grandparents residing in rural Kentucky. This research design provided data that allowed description of participating rural grandparents residing in Western Kentucky, as well as a description of the variables that affected their physical and mental health. A mixed methods approach provided insight into the grandparents' perceptions of the physical and mental health effects that have occurred since gaining custody of their grandchildren. For the mixed methods approach, a convergent design was used, which is implementation of the quantitative and qualitative data collection and analyses simultaneously followed by merging of the two sets of results (Creswell \& Plano Clark, 2011). The convergent mixed methods design results in a broader understanding of a subject.

\section{Sample and Setting}

This study focused on grandparents raising their grandchildren in rural Western Kentucky. The convenience sample of grandparents was recruited using flyers posted at churches, health clinics, hospitals, schools, and beauty salons as well as a press release produced by Hopkinsville Community and Technical College. This press release resulted in an interview with the principle investigator (PI) on a local radio station. Additionally, grandparent support groups in Western Kentucky were contacted to solicit participation in the study. One support group in the geographic area was the Lyon County Family Resource and Youth Service Center Grandparents Raising Grandchildren Support Group. They invited the PI to speak at a support group meeting and solicit interest in study participation. Snowball sampling was used as an additional recruitment tool as participants identified other grandparents interested in the study. The goal in participant recruitment was to obtain a sample of grandparents in all stages of health, not just ill health, so confounding would be limited. Admittance into the study was open to anyone who met the inclusion/exclusion criteria as outlined below. 


\section{Inclusion Criteria}

The criteria for inclusion were the following:

1. Grandparent must reside in one of the following Kentucky counties: Caldwell, Christian, Crittenden, Hopkins, Livingston, Lyon, Muhlenberg, Todd, or Trigg.

2. The participating grandparent had formal or informal custody of one or more grandchildren, based on self-report.

3. The grandchildren were currently living with the participating grandparent on a full-time basis.

4. The grandchildren's parents were not currently living in the participating grandparent's home.

5. The participating grandparent was responsible for all needs of the grandchildren.

6. The participant was able to read and speak English.

7. Only the self-reported primary caregiver was enrolled (i.e., one grandparent per household).

\section{Exclusion Criteria}

Exclusion criteria included grandparents who were babysitting on a full- or parttime basis and non-caregiving grandparents.

\section{Sample Description}

This study included a convenience sample of 21 custodial grandparents raising their grandchildren and residing in the Pennyrile Region of Western Kentucky. The majority of the participants were obtained by snowball sampling from community members who were acquainted with custodial grandparents and made the introduction to the researcher. Five of the participants were recruited from a single grandparent support group. All grandparent participants had formal or informal custody of 1 or more grandchildren without the children's parents residing in the home.

This study presented several challenges in recruiting. Although the PI learned of numerous grandparents via snowball sampling, many were not willing to participate. While the reasons for recruitment difficulties are unknown, the impression given by encounters with potential participants was that the grandparents were very busy. For 
example, on a few occasions a grandparent did not keep a scheduled appointment with the PI. Some of these grandparents were able to be contacted by phone and rescheduled as they had forgotten their appointment. Other grandparents could never be reached by phone to reschedule. While recruitment flyers were distributed to numerous places in the research area and a radio interview was conducted providing the PI's contact information, very few participants responded to these recruitment strategies.

\section{Instrumentation}

Several pencil and paper instruments were used to collect data on the grandparents' physical and mental health, stress, coping, and support resources. Instruments used for this study included: Grandparent Demographic Data Form, Short Form-36 General Health Survey, Centers for Epidemiologic Studies for Depression Scale, Parenting Stress Index Short Form, Ways of Coping Questionnaire, and Family Support Scale. Additionally, focus group interviews were conducted to obtain the grandparents' perceptions of how their physical and mental health was affected by stress, ability to cope, and availability of support resources.

\section{Grandparent Demographic Data Form}

Demographic data were obtained on the custodial grandparents using a self-report questionnaire developed by the investigator (Appendix). The questionnaire included information on age in years, gender (male $=0$; female $=1$ ), race (African American $=0$; Caucasian $=1$; Hispanic $/$ Latino $=2$; Other $=3$ ), marital status (married/living with a partner $=1$; not married, (i.e. separated, divorced, widowed, never married $=0$ ), employment status (employed $=0$; not employed $=1$ ), and educational level (years of formal education). In addition, the participants were asked to list their current medical conditions; healthcare services available; insurance status (no $=0$; yes $=1$; other $=2$ ) and type (private; Medicare; Medicaid); number, age in years, and gender of grandchildren; length of time with grandchildren in home (in months); and reason for custody of their grandchildren. Finally, the Grandparent Demographic Data Form included an item to assess a self-reported classification of residential area (rural $=0$; $\operatorname{suburban}=1$; urban/metropolitan=3). For any missing demographic data, a period (.) was used in the dataset to indicate that the data were missing.

\section{Short Form-36 General Health Survey}

The Short Form-36, version 2 General Health Survey (SF36v2) is a 36-item questionnaire that is a measure of functional health. According to Ware (2000), the framework organization for the instrument begins with two summary measures, physical health and mental health. Under the summary measures are eight scales that correlate to each summary measure (Ware, 2000). Physical Functioning, Role-Physical, and Bodily Pain are the scales that correlate the most to the physical health summary measure 
(McHorney, Ware, \& Raczek, 1993; Ware, 2000). Mental Health, Role-Emotional, and Social Functioning are the scales that correlate most with the mental health summary measure (McHorney et al., 1993; Ware, 2000). The three remaining scales, Vitality, General Health, and Social Functioning, can correlate with either summary measure, although General Health is correlated with the physical health summary measure and Vitality and Social Functioning are correlated to the mental health summary measure in the taxonomy of the SF-36 measurement model (Ware, 2000). The instrument contains 36 items that aggregate the eight scales (Ware, 2000).

The SF-36v2 contains items with a 5-choice response, with the exception of items $3 \mathrm{a}-\mathrm{j}$, which offer a 3-choice response. For most questions, the 5-choice responses range between "all of the time" and "none of the time". The 3-choice responses include 1) "yes, limited a lot"; 2) "yes, limited a little"; and 3) "no, not limited at all". Each response choice has a numerical value assigned ranging between 1 and 5. The scores are calculated for each scale, in relation to population norms, using norm-based scoring so each scale has the same mean (50) and same standard deviation (10). The use of normbased scoring is designed to simplify interpretation, with higher scores indicating better health (Ware, 2000; Ware et al., 2008). Group mean scale scores below 47 indicate health status below average (Maruish, 2011).

Reliability and validity of the SF36v2 have been widely tested as described by Ware (2000). The instrument has a high reliability in the general population and has an estimated alpha exceeding .90 for the physical and mental summary scores. Construct validity was confirmed during the instrument's development by comparing the results of the SF36v2 to numerous other widely used health measures with comparable results. Validity has also been confirmed by using the SF36v2 in numerous treatment-post treatment clinical studies. The SF36v2 has been used in grandparent samples in previous studies and has demonstrated reliability with Cronbach's alpha's of .71 to .96 (Goodman \& Silverstein, 2002; Kelley et al., 2000; Leder et al., 2007; Whitley et al., 2001). It is estimated to take less than 10 minutes to complete and has a Flesch-Kincaid reading level of 6.9 (Quality Metric Incoporated, 2009). Higher scores on the scales indicate better health for the participant (Leder et al., 2007).

\section{Center for Epidemiologic Studies for Depression Scale}

The Center for Epidemiologic Studies for Depression scale (CES-D) is a 20-item Likert-type questionnaire to measure current levels of depressive symptoms in the general population. The CES-D is a reliable measure with an alpha of .85 in the general population. Validity of the CES-D has been established in a variety of clinical settings with correlations noted between the CES-D and other widely used instruments measuring depression. It has also demonstrated validity in comparison studies of its use with psychiatric inpatient and the general population (Radloff, 1977). This instrument has been used in previous studies of grandparents raising grandchildren (Goodman \& Silverstein, 2002; Linsk et al., 2009; Musil, 1998, 2000; Musil et al., 2009) and has shown an alpha reliability of .89 to .91 in this population (Goodman \& Silverstein, 2002; 
Musil, 1998, 2000; Musil et al., 2009). Completion of the instrument takes 5-10 minutes and the instrument has a Flesch-Kincaid reading level of 6. Scores on the CES-D of 16 or higher indicate a risk for clinical depression (Musil et al., 2009).

\section{Parenting Stress Index, Short Form}

The Parenting Stress Index, short form (PSI/SF) is a 36-item, Likert-type questionnaire to measure Total Stress (TS) and the three subscales of Parental Distress (PD), Parent-Child Dysfunctional Interaction (PCDI), and Difficult Child (DC) in parentchild interactions (Trail Ross \& Aday, 2006). This instrument has a high reliability with a Cronbach's alpha of .91 for TS, .87 for PD, .80 for PCDI, and .85 for DC. It has been used in studies of grandparents raising grandchildren with a reliability of .94 to .95 for the total stress scale and .86 to .92 for the three subscales (Leder et al., 2007; Musil, 1998, 2000; Trail Ross \& Aday, 2006). According to Abidin (1995), the PSI/SF was found to be highly correlated to the full-length PSI. However, it has not undergone validity testing on its own. The full-length PSI has been used in numerous studies to provide evidence of construct and predictive validity with a variety of populations including special populations (Abidin, 1995). The full-length PSI has also had correlation established with other widely used measures of parenting stress to strengthen its validity (Abidin, 1995). It is estimated to require 10 minutes to complete the instrument, which has a $5^{\text {th }}$ grade reading level (Abidin, 2011). According to Abidin (1995), grandparents with TS scores at or above the $90^{\text {th }}$ percentile are experiencing significant levels of stress.

\section{Ways of Coping Questionnaire}

The Ways of Coping Questionnaire (WCQ) is a 66-item, Likert-type questionnaire that measures coping strategies. The WCQ was developed by Lazarus and Folkman in 1984 (Folkman \& Lazarus, 1988). Reliability and validity testing has been conducted by Lazarus and Folkman (1988) for the WCQ. In a study where five interviews were conducted with participants, reliability testing was performed by examining Cronbach's alpha, which were at the low end of traditional but higher than other coping instruments available for use (Folkman \& Lazarus, 1988). According to Lazarus and Folkman (1988), "Evidence of construct validity is found in the fact that the results of our studies are consistent with our theoretical predictions" (p. 13) and the instrument's use in other studies. The WCQ has eight subscales, with alpha levels reflecting reliability that include confrontive coping (alpha .70), distancing (alpha .61), self-controlling (alpha .70), seeking social support (alpha .76), accepting responsibility (alpha .66), escape avoidance (alpha .72), planful problem solving (alpha .68), and positive reappraisal (alpha .79; Folkman \& Lazarus, 1988). The 66-item WCQ has been used in grandparent raising grandchildren research (Musil, 1998, 2000). The instrument

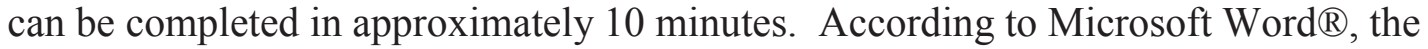
Flesh-Kincaid reading grade level is 4.5 for the WCQ. A higher score on a subscale of the WCQ indicates a frequent use of that coping strategy (Folkman \& Lazarus, 1988). 


\section{Family Support Scale}

The Family Support Scale (FSS) is an 18-item, five-point Likert-type questionnaire that measures the helpfulness of formal and informal support services (Leder et al., 2007). Reliability with a coefficient alpha of .79 was established in a study of 224 parents of children with disabilities and test-retest administration (Dunst et al., 2007). Construct validity was established by significant correlation with the Questionnaire on Resources and Stress (Dunst et al., 2007). It has been used in previous grandparent raising grandchildren research (Kelley et al., 2000; Leder et al., 2007) with a Cronbach's alpha of .65 reported by Leder, Grinstead, and Torres (2007). Estimated time for completion is five minutes and higher scores indicate increased social support (Kelley et al., 2000).

\section{Procedure}

Permission to conduct the proposed study was obtained from the University's Institutional Review Board (IRB). Once potential participants contacted the principal investigator (PI) expressing an interest in the study, the study was briefly explained and if the participant was willing, an interview appointment was made to meet with the PI in a place of the custodial grandparent's choosing and convenience. Most participants elected to meet in their homes. During the interview, informed consent was obtained then the study instruments were completed by the grandparent. The PI offered assistance and clarification of the instrument instructions and items when requested by the grandparent. Upon completion of the study instruments, interest in participating in a focus group at a later date was solicited. Each participant received \$20.00 upon completion of the questionnaires. Upon completion, questionnaires were coded to protect the identity of the participant.

Data collection for this study began in October 2011 and continued until February 2012. Since recruitment was delayed by the holiday season, the focus groups were scheduled after a sufficient number of participants had completed the study instruments. The PI contacted all grandparent participants by telephone to schedule a focus group. Two focus groups were planned at locations convenient for the participants. The first focus group had four participants from a grandparent support group and the focus group was held at their usual meeting site. The second group had three participants and was held in a Hopkinsville Community and Technical College meeting room. At the beginning of the focus groups, all participants were reminded of the informed consent signed during the initial individual interview which addressed the focus groups as well. Once consent was reaffirmed verbally, the audiotaped focus groups began using a question script approved by the IRB. At the completion of each focus group, each grandparent received an additional $\$ 20$ for participating. The audiotaped data was transcribed by the PI for both focus groups. 


\section{Data Analysis}

Statistical Analysis Software (SAS) 9.2 was used to conduct all statistical analyses to describe the study sample and address specific aims one through three. QualityMetric Health Outcomes ${ }^{\circledR}$ Scoring Software 4.0 was used to obtain the SF36v2 scale and subscale scores for use in the SAS statistical analyses. NVivo9 was used to analyze the qualitative data for specific aim four. In the following section, the analysis techniques are presented for each specific aim. An alpha level of 0.05 was used for determining statistical significance.

\section{Specific Aim One}

Describe the demographic characteristics (age, gender, race, marital status, socioeconomic status, number of grandchildren in home, age, and gender of grandchildren in home, length of time with grandchildren in home, reason for custody, and classification of residential area) of rural-dwelling custodial grandparents. Along with the demographic characteristics, grandparents were asked to report any medical conditions or health problems, insurance status and type, and availability of healthcare services.

Simple descriptive statistics were obtained to describe the study sample using the frequency and univariate procedures. The frequency procedure was used to determine percentages for gender, race, marital status, employment status, insurance status, residential area classification, and number of children in home. The univariate procedure was used for all other demographic variables to obtain details on mean, median, standard deviations, extreme values, plots, and normality of data distribution. The continuous data were found to have been sampled from underlying normal distributions.

\section{Specific Aim Two}

Describe the physical and mental health status, stressors, coping, and social support of rural-dwelling custodial grandparents.

The instrument scores were analyzed using the univariate procedure to obtain mean, median, extreme values, and plots. Measures of central tendency were used to determine normality of data distribution. Distributions of the data were examined to determine if sampling was taken from underlying normal distributions. All instrument scores were determined to have been sampled from an underlying normally distributed population. A Student's T test was performed to analyze the relationship of employment with the SF36v2 physical component summary score; physical functioning and bodily pain subscale scores; and WCQ confrontive coping score. A Student's T test was also performed to analyze the relationship between marital status and the WCQ planful problem solving score and FSS total support scale score. Additionally, a least squares 
means were compared in the context of ANOVA to examine a relationship between number of children and the CES-D and SF36v2 vitality subscale scores.

\section{Specific Aim Three}

Examine the relationships among physical and mental health status, stressors, coping, and social supports of rural-dwelling custodial grandparents.

Since all data was determined to have been sampled from an underlying normal distribution, correlation analysis was conducted to estimate Pearson product moment correlation coefficients among all instrument scale and subscale scores as well as marital, employment, and insurance status, education in years, and number of children in custody.

\section{Specific Aim Four}

Explore grandparents' perceptions of the effects stressors, coping, and social supports have on their physical and mental health status.

The transcribed focus group data were analyzed using thematic content analysis. Codes were identified during the first analysis phase of the focus group data then merged into categories. Finally, the categories were analyzed for emerging themes from the data. Once the quantitative and qualitative data were analyzed separately, the findings were integrated to determine the extent of convergence or divergence of the data.

\section{Consideration of Human Subjects}

Consideration of human subjects was provided by use of an informed consent, explanation of the research risks, and protections to maintain confidentiality. The informed consent was approved by the University of Tennessee Health Science Center Institutional Review Board for use in this study. Consent to participate was obtained from each participant prior to completing the questionnaires or attending a focus group. The consent was explained to each participant as they read the document and questions were addressed as needed. Each participant was informed that participation in the study was voluntary and could be withdrawn at any time without penalty or loss. The consent outlined the procedure for the study, which included completion of the questionnaires and participation in a focus group.

Potential risks for the study were explained to each participant as part of the informed consent. While no physical risk was identified, the potential risks identified were loss of confidentiality, feeling uncomfortable with a question, and having voice recordings made. Participants were assured of every effort being made to protect confidentiality, as outlined below. Participants were reassured they would not be required to answer any question that made them feel uncomfortable or emotional in any 
way. During the focus groups, participants were assured that there were "no right or wrong answers to the questions" to promote a comfortable and open environment. Finally, participants were informed that if audiotaping their voice made them feel uncomfortable, they could elect not to participate or could withdraw participation in a focus group at any time.

Every effort was made to protect participants' confidentiality and these steps were explained during the consenting process. All information obtained from the participants was kept confidential. Participants were assigned an identification number to eliminate identification of their individual data. The PI is the only individual with access to the participants' information and master identification list. However, the University of Tennessee Health Science Center Institutional Review Board may be granted access to participant information and data in the course of their oversight activities. The master participant list was maintained in a separate locked file in the PI's research office. No participant personal information is used during the dissemination of the study results. 


\section{CHAPTER 4. RESULTS}

This chapter presents the results of the quantitative analysis, including a) descriptive statistics characterizing participating grandparents raising grandchildren in a rural-setting of Western Kentucky; b) a description of physical and mental health, stressors, coping, and social support for the study sample of rural-dwelling custodial grandparents; and c) an examination of the relationships among physical and mental health, stressors, coping, and social support for rural-dwelling custodial grandparents. Following these results, the qualitative analysis results will be reported to describe ruraldwelling custodial grandparents' perceptions of the effects of stressors, coping, and social support on their physical and mental health. Finally, the quantitative and qualitative results will be integrated to provide a more complete picture of rural-dwelling custodial grandparents in Western Kentucky.

\section{Quantitative Results}

\section{Rural-dwelling Custodial Grandparent Characteristics}

As summarized in Table 4-1 participants' characteristics are presented as frequencies, percentages, means, and standard deviations. The participants consisted of 21 custodial grandparents caring for 29 grandchildren. Most grandparents were female $(85.7 \%)$ and Caucasian (85.7\%) followed by African American (14.3\%). This distribution is congruent with the state of Kentucky consensus data as $87.8 \%$ of Kentucky residents are Caucasian, although only $7.85 \%$ of the population is African American (U. S. Census Bureau, 2012). The mean age was 59.8 years $(\mathrm{SD} \pm 8.7)$ with a mean education level of 12.9 years $(\mathrm{SD} \pm 2.0)$. Most grandparents were married $(61.9 \%)$ and unemployed (66.7\%), a category which included being retired or disabled. Most of the participants described the area in which they reside as rural $(85.7 \%)$. Most custodial grandparents (61.9\%) had health insurance (Table 4-1) and Medicare was the most frequent type, although most grandparents had two insurance types (Table 4-2). Many grandparents listed several current health problems with hypertension being the most common, although four were not currently experiencing any health concerns (Table 4-3). Most custodial grandparents used healthcare within their town of residence. However, some grandparents in this study reported needing a healthcare specialist (i.e., cardiologist or endocrinologist), which necessitated travelling approximately an hour to a larger city to access this level of healthcare.

In terms of the grandchildren under their care, most grandparents were caring for one grandchild. Most of the 29 grandchildren were male $(75.9 \%)$ with a mean age of 8.9 years $(\mathrm{SD} \pm 4.2)$. The length of time that grandparents had custody of their grandchildren ranged from 1 to 180 months (15 years), with half in custody between 12 and 84 months (1-7 years). The reasons for grandchildren being in the custody of their grandparents 
Table 4-1. Demographic Characteristics of a Sample of Rural-dwelling Custodial Grandparents Raising Grandchildren in Western Kentucky (N=21)

\begin{tabular}{|c|c|}
\hline Characteristics & $\begin{array}{c}\text { Sample } \\
\text { n(\%) }\end{array}$ \\
\hline \multicolumn{2}{|l|}{ Gender } \\
\hline Male & $3(14.3)$ \\
\hline Female & $18(85.7)$ \\
\hline \multicolumn{2}{|l|}{ Race } \\
\hline African American & $3(14.3)$ \\
\hline Caucasian & $18(85.7)$ \\
\hline Hispanic/Latino & $0 \quad(0)$ \\
\hline Other & $0 \quad(0)$ \\
\hline \multicolumn{2}{|l|}{ Marital Status } \\
\hline Not married & $8(38.1)$ \\
\hline Married/Living with another & $13(61.9)$ \\
\hline \multicolumn{2}{|l|}{ Employment } \\
\hline Not employed & $14(66.7)$ \\
\hline Employed & $7(33.3)$ \\
\hline \multicolumn{2}{|l|}{ Health Insurance Availability } \\
\hline No & $7(33.3)$ \\
\hline Yes & $13(61.9)$ \\
\hline Other $^{\mathrm{a}}$ & 1 (4.8) \\
\hline \multicolumn{2}{|l|}{ Description of Residential Area } \\
\hline Rural & $18(85.7)$ \\
\hline Suburban & $1(4.8)$ \\
\hline Metropolitan/Urban & $2(9.5)$ \\
\hline \multicolumn{2}{|l|}{ Number of Children in Custody ${ }^{b}$} \\
\hline 1 & $15(71.4)$ \\
\hline 2 & $4(19.1)$ \\
\hline 3 & $2(9.5)$ \\
\hline
\end{tabular}

Note. ${ }^{\mathrm{a}}$ Other health insurance availability included one grandparent who had a trust for

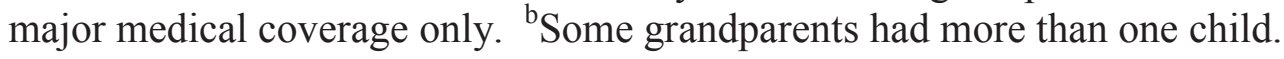


Table 4-2. Types of Insurance Reported by a Sample of Rural-dwelling Custodial Grandparents Raising Grandchildren in Western Kentucky ( $=21)$

\begin{tabular}{lc}
\hline Insurance Type & $\begin{array}{c}\text { Number of } \\
\text { Grandparents } \\
\text { Holding Type }\end{array}$ \\
\hline Medicare & 6 \\
Humana & 4 \\
Blue Cross/Blue Shield & 3 \\
Medicaid & 2 \\
Tricare Prime & 1 \\
Major Medical Trust & 1 \\
Retiree Insurance & 1 \\
\hline
\end{tabular}

Note. Grandparents could list more than one insurance type. 
Table 4-3. Current Medical Problems Reported by a Sample of Rural-dwelling Custodial Grandparents Raising Grandchildren in Western Kentucky $(\mathrm{N}=21)$

\begin{tabular}{lc}
\hline Medical Problem & $\begin{array}{c}\text { Number of } \\
\text { Grandparents } \\
\text { with Problem }\end{array}$ \\
\hline Hypertension & 10 \\
Diabetes & 4 \\
None & 4 \\
Gastroesophageal reflux disease & 4 \\
Hypothyroidism & 4 \\
Back pain/problems & 4 \\
Arthritis & 3 \\
Depression & 3 \\
High cholesterol & 2 \\
Anxiety & 2 \\
Renal Insufficiency & 2 \\
Heart failure & 1 \\
Knee replacement & 1 \\
Pseudotumor cerebri & 1 \\
Cerebral vascular accident (stroke) & 1 \\
Obesity & 1 \\
Atrial fibrillation & 1 \\
Blood clots & 1 \\
Diverticulitis & 1 \\
Peripheral vascular disease & 1 \\
Asthma & 1 \\
Displaced hip & 1 \\
Sinus problems & 1 \\
Lymphoma & 1 \\
\hline &
\end{tabular}

Note. Grandparents could list more than one current health problem. 
varied; the most common reason was drug/alcohol abuse by the biological parents (Table 4-4). However, many grandparents gave several reasons for the children's removal.

\section{Physical and Mental Health, Stressors, Coping, and Social Support Scores}

Scores based on self-assessments for physical and mental health, stressors, coping, and social support are summarized in Table 4-5. The range of scores for all SF36v2 scales and subscales are based on the range of possible norm-based scores. Group mean scores below 47 indicate limitations in a particular area (Maruish, 2011). The physical component summary (PCS) score indicates the degree of limitations in a) self-care; b) physical, social, and role activities; c) bodily pain; d) frequent tiredness; and e) health rated as "poor". These grandparents had a mean score on the physical component summary below $47(M=42.5, S D \pm 12.9)$ indicating some physical limitations. Lower scores for the mental component summary (MCS) score indicate a) frequent psychological distress, b) social and role disability due to emotional problems, and c) health rated as "poor". The mean score for these grandparents was just at the 47 threshold score $(M=47.5, S D \pm 13.1)$ indicating average mental health status. The SF36v2 contains 8 subscales focusing on particular physical and mental health components. Physical functioning indicates the participant's ability to perform physical activities including bathing, dressing, and vigorous activities with or without limitations. Norm-based scoring places the average at 50 for all scales and subscales. The mean norm-based score of these participants was $41.3(S D \pm 12.5)$ indicating some limitations in physical functioning. The ability to conduct daily work or other physical activities is indicated by the role physical score and again, the mean score was $43.0(S D \pm 12.7)$ indicating limitations in this area. The bodily pain subscale indicates the degree to which pain interferes with functioning. These participants had a mean norm-based score of 43.2 $(S D \pm 12.7)$ indicating some interference from bodily pain in daily activities. General health is another subscale on the SF36v2 that indicates how the person rates their overall health. These participants rated their general health as below average $(M=45.9, S D \pm$ 13.8). Vitality is another area of measurement and indicates how much of the time a person feels tired/worn out or full of pep and energy. Vitality for these participants was average $(M=47.6, S D \pm 14.4)$. Social functioning and role emotional were below average for this group of grandparents with a mean norm-based scores of 45.4 (SD \pm $11.7)$ and $41.8(S D \pm 12.6)$, respectively. These subscales indicate whether a person is able to perform normal social activities and work without interference of physical or emotional problems. Finally, the mental health subscale received the highest norm-based score with a mean of $48.5(S D \pm 12.7)$, which indicates average mental health functioning. This subscale indicates the degree to which participants feel peaceful, happy and calm. Based on these findings, this group of grandparents demonstrated some limitations in all but two of the subscales, vitality and mental health. However, these two scores were still below the overall norm score of 50. Based on their physical component summary scale score, the study grandparents had more limitations in their physical abilities than their mental health functioning. 
Table 4-4. Reasons for Custody of Grandchildren Reported by a Sample of Rural-dwelling Custodial Grandparents Raising Grandchildren in Western Kentucky (N=21)

\begin{tabular}{lc}
\hline Reasons & $\begin{array}{c}\text { Number of } \\
\text { Grandparents }\end{array}$ \\
\hline Drug/Alcohol abuse & 8 \\
Neglect & 5 \\
Poor parenting skills & 4 \\
$\quad$ irresponsible parents & \\
Parent lives/works out of town & 2 \\
Abuse by parent(s) & 2 \\
Parent incarceration & 2 \\
Parent without job/home & 2 \\
Truancy & 1 \\
Parent mental health disorder & 1 \\
Parent health problems & 1 \\
Helps grandparents & 1 \\
Parent died & 1 \\
Parent doesn't want child & 1 \\
\hline
\end{tabular}

Note. Grandparents could list more than one reason for custody of grandchildren. 
Table 4-5. Description of Self-reported Physical and Mental Health, Stress, Coping, and Social Support for a Sample of Rural-dwelling Custodial Grandparents Raising Grandchildren in Western Kentucky $(\mathrm{N}=21)$

\begin{tabular}{|c|c|c|c|c|}
\hline Instruments & $M$ & \pm & $S D$ & $\begin{array}{c}\text { Range of } \\
\text { Scores }\end{array}$ \\
\hline \multicolumn{5}{|l|}{ Short Form-36 Version 2} \\
\hline Physical Component Summary & 42.5 & \pm & 12.9 & $4-71$ \\
\hline Mental Component Summary & 47.5 & \pm & 13.1 & $2-74$ \\
\hline Physical Functioning & 41.3 & \pm & 12.5 & $15-57$ \\
\hline Role Physical & 43.0 & \pm & 12.7 & $18-57$ \\
\hline Bodily Pain & 43.2 & \pm & 12.7 & $20-62$ \\
\hline General Health & 45.9 & \pm & 13.8 & $16-64$ \\
\hline Vitality & 47.6 & \pm & 14.4 & $21-71$ \\
\hline Social Functioning & 45.4 & \pm & 11.7 & $12-57$ \\
\hline Role Emotional & 41.8 & \pm & 12.6 & $9-56$ \\
\hline Mental Health & 48.5 & \pm & 12.7 & $8-64$ \\
\hline \multicolumn{5}{|c|}{ Centers for Epidemiologic Studies-Depression } \\
\hline Total Score & 12.3 & \pm & 11.3 & $0-60$ \\
\hline \multicolumn{5}{|l|}{ Parenting Stress Index/Short Form } \\
\hline Total Score Percentile & 48.8 & \pm & 35.8 & $1-99+$ \\
\hline \multicolumn{5}{|l|}{ Ways of Coping Questionnaire } \\
\hline Confrontive Coping Raw Score & 6.6 & \pm & 3.0 & $0-18$ \\
\hline Distancing Raw Score & 6.3 & \pm & 4.1 & $0-18$ \\
\hline Self-Controlling Raw Score & 9.4 & \pm & 4.3 & $0-21$ \\
\hline Seeking Social Support Raw Score & 6.4 & \pm & 4.1 & $0-18$ \\
\hline Accepting Responsibility Raw Score & 3.8 & \pm & 1.9 & $0-12$ \\
\hline Escape-Avoidance Raw Score & 5.6 & \pm & 4.0 & $0-24$ \\
\hline Planful Problem Solving Raw Score & 10.1 & \pm & 3.0 & $0-18$ \\
\hline Positive Reappraisal Raw Score & 10.3 & \pm & 4.3 & $0-21$ \\
\hline \multicolumn{5}{|l|}{ Family Support Scale } \\
\hline Total Support Score & 30.2 & \pm & 11.8 & $0-95$ \\
\hline
\end{tabular}

Note. Range of scores reflects range of possible scores for each scale or subscale of the instrument. Short Form-36 version 2 scores are calculated using norm-based scoring. 
The Center for Epidemiological Studies for Depression (CES-D) scale is used as a screening tool for depressive symptomology. Scores of 16 or higher indicate a risk for clinical depression. For these participants, the mean score for the CES-D was 12.3 $(S D \pm 11.3)$ indicating low levels of depressive symptomology (Table 4-5). This also corresponds to the study sample's average mental health scores on the SF36v2. The Parenting Stress Index, short form (PSI/SF) total score percentile indicates the overall level of parenting stress an individual is experiencing. Total stress scores at or above the $90^{\text {th }}$ percentile signify clinically significant levels of stress. These participants had a mean stress percentile of $48.8(S D \pm 35.8)$ indicating low levels of parenting stress.

The Ways of Coping Questionnaire (WCQ) has several subscales that indicate the type of coping behaviors that participants prefer. Higher scores on the subscales indicate the frequent use of that coping behavior. The top two coping behaviors preferred by this group of grandparents were positive reappraisal with a mean raw score of $10.3(S D \pm 4.3$, range $0-21)$ and planful problem solving with a mean raw score of $10.1(S D \pm 3.0$, range 0-18). Positive reappraisal describes a person's efforts to focus on personal growth and create positive meaning while planful problem solving describes problem-focused efforts to alter the situation using an analytical approach (Folkman \& Lazarus, 1988). Selfcontrolling was the third coping behavior preferred by the group with a score of 9.4 $(S D \pm 4.3)$, which describes the efforts by a person to control his or her own feelings and actions. Finally, the Family Support Scale (FSS) indicates the amount of perceived support the family receives. Higher scores indicate increased social support. These grandparents scored a mean of $30.2(S D \pm 11.8)$ indicating that applicants reported receiving below average social support.

Some demographic variables were found to have significant relationships with physical health, coping, and social supports. Employed custodial grandparents $(\mathrm{N}=7)$, compared with unemployed grandparents, had higher scores on the SF36v2 physical component summary scale and physical functioning and bodily pain subscales (Table 4-6). This indicates that grandparents who were employed had fewer physical health limitations when compared to unemployed grandparents. Coping strategy varied by employment status with unemployed custodial grandparents $(n=14)$ preferring the confrontive coping strategy more often than employed custodial grandparents (Table 4-6). Custodial grandparents' coping style differed by marital status. Married grandparents preferred the planful problem solving coping strategy when compared to unmarried grandparents (Table 4-7). Married custodial grandparents reported more social support than unmarried grandparents (Table 4-7). Some mental health scores differed by the number of custodial grandchildren grandparents cared for (Table 4-8). Custodial grandparents $(\mathrm{N}=2)$ with three children in custody had a mean CES-D score of $34.0(p<.05)$ compared to a score of 10.1 for grandparents with one grandchild. However, this result may be related to outliers in the CES-D scores, such as a custodial grandmother with three grandchildren. The mean SF36v2 vitality subscale score of 25.6 $(p<.05)$ for the custodial grandparents with three grandchildren was also significantly different than that of grandparents with one grandchild. Results also suggested that increasing grandparent age was associated with decreased vitality, increased depressive symptomatology, and more infrequent preference of accepting responsibility as a coping 
Table 4-6. Comparisons of Self-reported Physical Health and Coping Strategies for Rural-dwelling Custodial Grandparents Raising Grandchildren in Western Kentucky Based on Employment Status

\begin{tabular}{lcccc}
\hline Variables & n & Mean & $\begin{array}{c}\text { Standard } \\
\text { Error }\end{array}$ & $\boldsymbol{p}$ Value \\
\hline $\begin{array}{l}\text { Short Form-36 Version 2 (SF36v2) } \\
\text { Physical Component Summary }\end{array}$ & 14 & 38.2 & 3.1 & .03 \\
$\begin{array}{l}\text { Unemployed } \\
\text { Employed }\end{array}$ & 7 & 51.1 & 4.5 & \\
SF36v2 Physical Functioning & & & & \\
Unemployed & 14 & 36.5 & 2.9 & .01 \\
Employed & 7 & 50.7 & 4.0 & \\
SF36v2 Bodily Pain & & & & \\
Unemployed & 14 & 39.1 & 3.2 & .03 \\
Employed & 7 & 51.5 & 4.0 & \\
Ways of Coping Questionnaire & & & & \\
Confrontive Coping & & & & \\
Unemployed & 14 & 7.6 & 0.6 & \\
Employed & 7 & 4.6 & 1.2 & \\
\hline
\end{tabular}

Note. Student's T Test was used for this analysis. 
Table 4-7. Comparisons of Self-reported Coping Strategies and Social Support for Rural-dwelling Custodial Grandparents Raising Grandchildren in Western Kentucky Based on Marital Status

\begin{tabular}{lcccc}
\hline Variables & n & Mean & $\begin{array}{c}\text { Standard } \\
\text { Error }\end{array}$ & $\boldsymbol{p}$ Value \\
\hline $\begin{array}{l}\text { Ways of Coping Questionnaire } \\
\text { Planful Problem Solving Score }\end{array}$ & & & & \\
Not married & 8 & 8.5 & 1.0 & .05 \\
Married & 13 & 11.1 & 0.8 & \\
& & & & \\
Family Support Scale Total Scale Score & & & & \\
Not married & 8 & 23.3 & 2.9 & .03 \\
Married & 13 & 34.5 & 3.3 & .03 \\
\hline
\end{tabular}

Note. Student's T Test was used for this analysis.

Table 4-8. Effect of Number of Children on Self-reported Mental Health for Rural-dwelling Custodial Grandparents Raising Grandchildren in Western Kentucky

\begin{tabular}{lrrr}
\hline Variables & n & LSMean & $\begin{array}{c}\text { Standard } \\
\text { Error }\end{array}$ \\
\hline Centers for Epidemiological Studies for & & & \\
Depression & 15 & 10.1 & 2.4 \\
One child & 4 & 9.5 & 4.6 \\
Two children & 2 & 34.0 & 6.5 \\
Three children & & & \\
Short Form-36 Version 2 Vitality Subscale & & & \\
One child & 15 & 51.9 & 3.2 \\
Two children & 4 & 42.7 & 6.2 \\
Three children & 2 & 25.6 & 8.8 \\
\hline
\end{tabular}

Note. Analysis of variance (ANOVA) was used for these analyses. Comparisons were made among least-squares means (LSMean). 
strategy. In general, some differences in self-assessments were associated with particular demographic characteristics. However, most self-assessments were independent of these.

\section{Relationships among Health, Stressors, Coping, and Social Support}

The relationships among the study variables are summarized in a matrix depicting estimated Pearson product-moment correlation coefficients (Table 4-9). The significant internal correlations of the SF36v2 and the WCQ were expected within instruments. The CES-D was negatively correlated with both the physical component summary $(r=-.46)$ and mental component summary $(r=-.91)$ measures as well as all eight subscales of the SF36v2 (Table 4-9). These findings indicate that increasing depressive symptomatology was associated with decreasing levels of physical and/or mental health functioning. Parenting stress had a moderate negative correlation with the SF36v2 mental component summary measure. Therefore, grandparents, who had more parenting stress, were experiencing more psychological and emotional distress. The Parenting Stress Index, short form was also moderately and negatively correlated with the SF36v2 vitality, social functioning, role emotional, and mental health subscales (Table 4-9). Stress also had a significant positive correlation with depressive symptomatology $(r=.58)$ indicating that as stress the grandparent was experiencing increased, he or she reported a greater number of depression symptoms.

Several of the WCQ subscales (confrontive coping, distancing, self-controlling, and escape avoidance) were negatively correlated with components of the SF36v2, indicating an increased use of those coping strategies was associated with poorer physical and mental health (Table 4-9). Interestingly, the WCQ accepting responsibility coping strategy subscale also had significantly negative correlations with role physical, bodily pain, general health, vitality, and social functioning SF36v2 subscales (Table 4-9). This suggests that the more these grandparents used the accepting responsibility coping strategy, the more limitations they had with their health. This finding was also confirmed by a significant positive correlation of the accepting responsibility coping strategy with the CES-D scores $(r=.44)$. The WCQ escape avoidance coping strategy was also significantly and positively associated with the more frequent depression symptoms on the CES-D $(r=.72)$. In addition, there was a moderately significant positive correlation between the WCQ escape avoidance coping strategy and the Parenting Stress Index/Short Form $(r=.52)$. The Family Support Scale score for these grandparents was significantly correlated with all of the SF36v2 scales and subscales, indicating more social support was associated with better health ratings (Table 4-9). The Family Support Scale was found to have a significant negative correlation with both the CES-D $(r=-.58)$ and the WCQ escape avoidance coping strategy $(r=-0.49)$. Overall, the quantitative findings suggest relationships among stress, depression, and lack of social support; these findings were reportedly associated with physical and mental health. For a more complete picture of this sample of rural-dwelling custodial grandparents, the findings of the qualitative data analysis must be considered. 
Table 4-9. Relationships among Physical and Mental Health, Stressors, Coping, and Social Support for Ruraldwelling Custodial Grandparents Raising Grandchildren in Western Kentucky $(d f=24)$

\begin{tabular}{|c|c|c|c|c|c|c|c|c|c|c|c|}
\hline Variable & 1 & 2 & 3 & 4 & 5 & 6 & 7 & 8 & 9 & 10 & 11 \\
\hline 1. SFPCS $^{\dagger}$ & - & & & & & & & & & & \\
\hline 2. $\mathrm{SFMCS}^{\dagger}$ & .31 & - & & & & & & & & & \\
\hline 3. $\mathrm{SFPF}^{\dagger}$ & $.95 *$ & .28 & - & & & & & & & & \\
\hline 4. $\mathrm{SFRP}^{\dagger}$ & $.81 *$ & $.61^{*}$ & $.75^{*}$ & - & & & & & & & \\
\hline 5. $\mathrm{SFBP}^{\dagger}$ & $.78^{*}$ & $.55^{*}$ & $.70 *$ & $.57 *$ & - & & & & & & \\
\hline 6. $\mathrm{SFGH}^{\dagger}$ & $.86^{*}$ & $.62 *$ & $.81^{*}$ & $.85^{*}$ & $.75^{*}$ & - & & & & & \\
\hline 7. $\mathrm{SFVT}^{\dagger}$ & $.75^{*}$ & $.69 *$ & $.68^{*}$ & $.77 *$ & $.71^{*}$ & $.84 *$ & - & & & & \\
\hline 8. $\mathrm{SFSF}^{\dagger}$ & $.59 *$ & $.87 *$ & $.51^{*}$ & $.73 *$ & $.73^{*}$ & $.82 *$ & $.71 *$ & - & & & \\
\hline 9. $\mathrm{SFRE}^{\dagger}$ & $.45^{*}$ & $.90^{*}$ & $.47 *$ & $.73 *$ & $.51^{*}$ & $.68^{*}$ & $.68^{*}$ & $.80 *$ & - & & \\
\hline 10. $\mathrm{SFMH}^{\dagger}$ & .38 & $.93 *$ & .37 & $.59 *$ & $.64^{*}$ & $.61 *$ & $.63 *$ & $.84 *$ & $.76^{*}$ & - & \\
\hline 11. CESD & $-.46^{*}$ & $-.91 *$ & -.39 & $-.68 *$ & $-.60 *$ & $-.72 *$ & $-.78 *$ & $-.87 *$ & $-.79 *$ & $-.87 *$ & - \\
\hline 12. PSITOTALPER & -.13 & $-.56 *$ & -.11 & -.35 & -.17 & -.33 & $-.49 *$ & $-.44 *$ & $-.47 *$ & $-.47 *$ & $.58 *$ \\
\hline 13. WCQCCRAW & $-.50 *$ & .05 & $-.52 *$ & -.33 & -.28 & -.36 & -.31 & -.06 & -.11 & .02 & .04 \\
\hline 14. WCQDRAW & -.36 & -.33 & -.35 & -.23 & $-.57 *$ & -.35 & -.34 & -.36 & -.18 & $-.51 *$ & .37 \\
\hline 15. WCQSCRAW & -.30 & -.38 & -.38 & -.27 & -.27 & $-.46^{*}$ & -.29 & -.42 & -.41 & -.38 & .22 \\
\hline 16. WCQSSSRAW & -.12 & .10 & -.00 & -.15 & -.04 & -.08 & -.01 & .02 & .13 & .06 & -.13 \\
\hline 17. WCQARRAW & -.38 & -.39 & -.21 & $-.48 *$ & $-.44 *$ & $-.45 *$ & $-.47 *$ & $-.46^{*}$ & -.29 & -.41 & $.44^{*}$ \\
\hline 18. WCQEARAW & -.38 & $-.69 *$ & -.38 & $-.54 *$ & $-.48 *$ & $-.55 *$ & $-.52 *$ & $-.67 *$ & $-.56^{*}$ & $-.76^{*}$ & $.72 *$ \\
\hline 19. WCQPPSRAW & .21 & .07 & .20 & .10 & .12 & .20 & .32 & .16 & .09 & -.04 & -.15 \\
\hline 20. WCQPRRAW & .03 & -.18 & .09 & -.04 & -.17 & -.06 & .07 & -.15 & -.12 & -.25 & .06 \\
\hline 21. FSSTS & $.62 *$ & $.52 *$ & $.63^{*}$ & $.53 *$ & $.61^{*}$ & $.70 *$ & $.65^{*}$ & $.63 *$ & $.59 *$ & $.48^{*}$ & $-.58^{*}$ \\
\hline
\end{tabular}


Table 4-9. Continued

\begin{tabular}{lccccccccc}
\hline Variable & $\mathbf{1 2}$ & $\mathbf{1 3}$ & $\mathbf{1 4}$ & $\mathbf{1 5}$ & $\mathbf{1 6}$ & $\mathbf{1 7}$ & $\mathbf{1 8}$ & $\mathbf{1 9}$ & $\mathbf{2 0}$ \\
\hline 12. PSITOTALPER & - & & & & & & & & \\
13. WCQCCRAW & .01 & - & & & & & & & \\
14. WCQDRAW & .01 & .32 & - & & & & & & \\
15. WCQSCRAW & .28 & .36 & .37 & - & & & & & \\
16. WCQSSSRAW & -.08 & .41 & -.09 & .08 & - & & & & \\
17. WCQARRAW & .03 & .22 & .27 & -.04 & .27 & - & & & \\
18. WCQEARAW & $.52 *$ & .41 & $.60 *$ & $.46^{*}$ & .07 & $.44^{*}$ & - & & \\
19. WCQPPSRAW & -.42 & -.03 & .06 & -.14 & .04 & $.49 *$ & .02 & - & \\
20. WCQPRRAW & -.26 & .05 & .20 & -.00 & $.44 *$ & $.48^{*}$ & .17 & $.61 *$ & - \\
21. FSSTS & -.38 & -.24 & -.29 & -.28 & .14 & -.14 & $-.49 *$ & .40 & -.11 \\
\hline
\end{tabular}

Note. Estimated Pearson product-moment correlation coefficients. SFPCS = Short Form Physical Component Summary; SFMCS = Short Form Mental Component Summary; $\mathrm{SFPF}=$ Short Form Physical Functioning; SFRP $=$ Short Form Role Physical; SFBP = Short Form Bodily Pain; SFGH = Short Form General Health; SFVT = Short Form Vitality; SFSF = Short Form Social Functioning; SFRE = Short Form Role Emotional; $\mathrm{SFMH}=$ Short Form Mental Health; CESD = Centers for Epidemiologic Studies Depression; PSITOTALPER = Parenting Stress Index Total Percentile; WCQCCRAW = Ways of Coping Questionnaire Confrontive Coping raw score; WCQDRAW = Ways of Coping Questionnaire Distancing raw score; WCQSCRAW = Ways of Coping Questionnaire Self-controlling raw score; WCQSSSRAW = Ways of Coping Questionnaire Seeking Social Support raw score; WCQARRAW = Ways of Coping Questionnaire Accepting Responsibility raw score; WCQEARAW = Ways of Coping Questionnaire Escape-Avoidance raw score; WCQPPSRAW = Ways of Coping Questionnaire Planful Problem Solving raw score; WCQPRRAW = Ways of Coping Questionnaire Positive Reappraisal raw score; FSSTS = Family Support Scale total score.

${ }^{\dagger}$ norm-based score. ${ }^{*} p<.05$. 


\section{Qualitative Results}

The qualitative results revealed the rural-dwelling custodial grandparents' perceptions of the effects stressors, coping, and social supports have on their physical and mental health status. Five themes arose from the focus group data analysis and are discussed in this section.

\section{"Physical Health Isn't a Problem"}

The custodial grandparents in this study did not perceive physical health as a limitation. Most grandparents reported having health problems such as diabetes, hypertension, or arthritis but said they are still able to meet their grandchildren's needs. They described themselves as being very active in school activities and committees as well as taking their grandchildren to a local water park. In a few cases, grandparents would use informal supports, such as younger church members or neighbors, to take their grandchild on outings that were more physically challenging, like sledding or skating. However, custodial grandparents in this study endeavored to stay as active as possible with their grandchildren. This was demonstrated by one grandparent who said, "I can tell I'm that age but I really don't feel 73. But, I mean, I know I'm there and I can tell that I can't run when I play kickball. They usually get me out because I can't run fast or there's things I can't do." Grandparents also reported they had health problems but that some of these developed before they obtained custody of their grandchildren or were inherited. A grandparent reported, "I'm riddled with arthritis. My whole family has it on my mother's side. You live with that. You get up every morning; you knew you don't sit around." Even health conditions that could potentially limit their mobility were not viewed as a problem as evidenced by one grandparent's statement: "I had knee replacement surgery a year ago in August, a year and a half ago. And I still have arthritis, I can feel it but, ah, that's not as stressful, that isn't the problem". Another aspect of physical health that grandparents discussed was keeping themselves physical healthy.

Grandparents emphasized the need to stay healthy for their grandchildren and other family members. They described efforts at staying physically active as illustrated by grandparent statements like, "I walked four miles this morning" and "I go to the Y probably three days a week because I have exercises the physical therapist wants me to do for my knees." In addition to physical activities, grandparents described the importance of eating healthy. Some grandparents stressed the importance of eating healthy because they or a family member had diabetes but suggested that this benefited the whole family. This was illustrated in a statement by one grandparent, "Well, having a diabetic in the house, we eat, we have to eat healthy. No sugar, no salt, we have to eat healthy." A few grandparents reported taking vitamins and supplements as an important component to staying healthy.

Finally, all grandparents noted the importance of making regular visits to the doctor. These doctors' visits occurred monthly, every 3 months, or annually but all 
stressed the importance of keeping their appointments as a component of staying physically healthy. However, one grandmother described difficulty keeping her monthly doctor's appointments as she did not have child care. While not part of this study's data collection, a few grandparents reported a lack of personal transportation and a reliance on neighbors and friends when they needed to leave the home. They did not report whether or not this was a factor in keeping medical appointments. Grandparents reported that they are satisfied with the quality and availability of healthcare within their towns. One grandparent summarized this perception by stating, "I think we're very fortunate. I've gone to the same doctor for many years. He's my age so I don't know when he's going to retire but, there are other good doctors here. We're fortunate." Next, the custodial grandparents discussed mental health.

\section{"Mental Health: I Need 'Me' Time"}

In this study, the grandparents' perception was that mental health is a bigger problem than physical health. Two grandparent statements highlight this perception: "I don't think it's all just physical. I think it has to do with mentally too" and "I think, our health, it's the emotional issues that we have to deal with, with these children". Grandparents discussed feeling sad or depressed as frequently as "a lot", "pretty often", or "every once in a while." When asked 'how often do you feel sad or depressed', one grandparent stated "Mine's just about every day." Then she burst into tears and said, "Well, a lot of things [make me sad and depressed]." This grandparent was in a current state of crisis and appropriate referrals were made during and after the focus group to facilitate its resolution. Most of the study grandparents discussed strategies they used against depression.

Grandparents highlighted a need to do something for themselves to maintain their mental health. One grandparent described using physical activity when feeling depressed by stating "I feel depressed for 2 or 3 days and I'll gradually get over it. If I can get out

for a walk, I get over it pretty quick." Other grandparents described efforts to deal with depression as "girlfriend time", using crafts, or "I give myself a talking to." One grandparent illustrated this point by saying, "If I didn't have my girlfriend time, I wouldn't be this happy. I'm convinced of that." A few grandparents stressed the importance of attending counseling services to help with feelings of depression. However, the majority of grandparents emphasized that the grandchildren were not the source of their depression, as illustrated in the following section on stressors.

\section{"Stress, That's the Problem"}

The study grandparents described numerous stressors that included a) grandchildren's needs and behaviors; b) relationship strain with spouse; c) difficult relationships with adult children; d) legal, financial, and health concerns; and e) feelings of isolation. All of the study grandparents described stress as being the biggest problem they faced. This was illustrated by one grandparent who stated, "Yeah, but it's stress 
whether you realize it is or not, I mean, sometimes, I get really upset but for the most part, just going day-by-day, I don't feel the stress but you know it's there. If it's got a little simmering of a doubt within you, it's stress. And I think stress is probably the number one cause of grandparents', perhaps, not being healthy." The other grandparents attending this focus group all indicated their agreement with this grandparent. Grandparents described having difficulty "shutting off their brain" and focusing on "the great responsibility we've been given." Some grandparents expressed a reluctance of being in the parent role again. One grandparent expressed this viewpoint by saying, "I don't have no good night's sleep. I got to be honest with you, I'm tired of being a grandparent. It's just tiresome! I don't know, just got to deal with it." Another confirmed this viewpoint by stating, "I'm tired. I'd like to be a grandparent, not a parent and right now, we're not grandparents, we're parents. And that's, well, God didn't intend for us to be that." Numerous stressors were identified by the grandparents and while all of the study grandparents denied that their grandchildren were sources of stress, some of the grandchildren's needs and behaviors could be a source of stress.

Grandparents described the emotional difficulties experienced by the grandchildren in their custody as being a source of stress. According to the grandparents, the grandchildren in their custody, no matter the age, were in various stages of coping with feelings of abandonment. This was illustrated in this comment by a grandparent: "She can't help but feel that maybe she's done something wrong to cause this." Another grandmother talked about her relationship with her grandson when she obtained custody by stating "He was young. He's hyperlexic so, you know, there was no such beast as me going to the store, he would just have a meltdown. You know, because if he couldn't have his mother, he wanted his grandmother. And if his grandmother left the house without him, then I guess he felt like being abandoned again." Many grandparents described the grandchildren's dependence on the stability provided by the grandparents. Another frequent emotional difficulty experienced by the grandchildren was their desire for a mother and father unit and experimentation with names they called the grandparents. One grandparent stated, "And it's something, I guess everybody's got it, you know, it's like, the momma and the daddy. They just want to call you that." A few grandparents talked about behavioral concerns with their grandchildren but the situations they described were with preteens and teens beginning the process of transitioning to young adulthood. Nevertheless, it caused stress in the home and between spouses.

Some study grandparents described strain within the relationship with their spouse. This strain was related to disagreement on how the grandchildren were being raised and disengagement by one spouse in raising the grandchildren. This was illustrated by one grandparent by explaining, "My biggest problem with my grandchild, granddaughter, is with my wife. Cause my wife, like I say, I was truthful, we just don't agree on many things regarding, you know, with the kids and you know, with our children and our granddaughter either, so. But, we get by, we try to avoid each other I think." Other grandparents described limited involvement by their spouse in raising the grandchildren by "mine won't get up and go anywhere or do anything. He wants to fish, period, that's it." However, other grandparents expressed their reliance on their spouse 
for support. One area that all grandparents discussed as a tremendous stressor was their relationship with the grandchildren's parents and occasionally other adult children.

Most grandparents talked extensively about the situations that necessitated removal of the grandchildren from the parents' custody. Sometimes it was the grandparent's adult child or the adult child's spouse. Most of the situations described involved drug use by the child's parents and child neglect. This was illustrated by one grandparent saying, "But her mom is in a homeless shelter in Owensboro and right now, they won't let her have a pass until she gets a job. And she hates workin' and, ah, but at least she's off drugs, we think." Some grandparents and their grandchildren had occasional contact with the children's parents during supervised visitation. However, others did not want the grandchildren's parent to know the location of the grandchildren for safety reasons. One grandparent, in the focus groups, with informal custody of three grandchildren was in the midst of a crisis with her adult daughter. She described a recent interaction with her daughter stating, "And that daughter of mine. Oooff. She got people claiming her kids on their taxes. I asked her for $\$ 150$ and she wouldn't give it to me. [crying by grandparent increased] They gonna cut my lights off [shut off electricity] Wednesday and she won't even help." Conflict with their adult children was the stressor most talked about during the focus groups and was a thread during most of the discussion. The conflicts with the grandchildren's parents were also linked with financial stressors experienced by the grandparents.

Grandparents shared their experiences with the legal system in gaining custody of their grandchildren. The challenges they faced were finding appropriate legal representation to gain custody, navigating the legal and social services system, and lacking familiarity with regulations for financial assistance, adoptions, and custody. Grandparents readily shared their knowledge with other grandparents in the group who were unaware of community resources and custody protections. Some grandparents also voiced a concern that a parent could decide to take the child back into their custody. This concern was illustrated by one grandparent stating, "And the worry about, if the parent is incarcerated, oh my goodness, when the parent gets out, you know, am I going to lose this child? And, course the longer you've raised them, the harder it would be and you keep in your head the best interest of the child, but the stress is still there." Legal issues were connected with financial stress in many cases.

Financial strain occurred for grandparents for several different reasons. There was the cost of gaining custody for some, as explained by one grandparent: "Financially, we were lucky, it only cost us $\$ 8000$ to keep our grandson safe. Not every grandparent gets off that easily, you know." Most grandparents discussed the need to apply for Temporary Assistance for Needy Families (TANF) to help make ends meet since gaining custody of their grandchildren. They also used various community resources for children's clothing, food assistance, school supplies, utility bills, and Christmas presents. Some grandparents had delayed getting medical care because of limited financial means. This was illustrated by one grandparent saying, "He's going to lose his feet pretty soon. So, you know, what do you do? You not get the amount of groceries and put some bills off? So, you can get him to a podiatrist that you're going to have to do something with, 
you know. And, he won't do that. You know, the money that he brings in goes for household, and then, like I said, you lose your feet, you're not going to work." One grandparent summarized financial stressors this way, "And I worry about money. It's hard financially."

Some grandparents also had health stressors like diabetes or needing back surgery. However, most of the grandparents worked on staying as healthy as possible for the grandchildren. One grandparent stated, "Cause you know, you're older and you want to stay healthy for them. I mean, you want to see them get out of school and on their own. You don't want to see them possibly have to go back or something happen and you not be there for them." For most grandparents in this study, health stressors were a small factor or nonexistent.

Isolation was the final stressor identified by the grandparents in this study. Some grandparents described a lack of someone to talk to about their situation. A few grandparents had moved to Western Kentucky from other states and had not formed close friendships in their new area. Other grandparents did not have friends that could relate to the issues they face. When questioned about friends that one grandparent meets with weekly, he stated, "We don't talk about anything like that." He also stated, "I don't have anybody to talk to about it. And I definitely can't talk to my wife about it cause we're opposite ends of the spectrum." Some grandparents did not have anyone that could watch the grandchildren, giving them some respite and time for themselves. All of these perceived stressors required the grandparents to use a variety of coping techniques, which are described in the next section.

\section{"Coping: I Just Have to Talk to Someone"}

Grandparents discussed their perceptions of coping with stress. One of the primary coping strategies they discussed was having someone to talk to about their situation. This was illustrated by one grandparent when she stated, "And once I found grandsplace.org online, ah, I'm on that chat room every night with the grands all across the world. And that keeps me, that keeps me sane, you know, I have become close friends with many of them. I've met them. I've spent time with them." Some grandparents did not have anyone to talk to about their situation but voiced a desire to have someone in that role. Grandparents also talked about "letting things go" and not adhering to schedules and routines as much, for example, if toys were picked up at the end of the day or housework. One grandparent summarized it this way, "I think for myself now, don't ask me why, but I think when the kids were home, it was like every night, they picked up everything off the floor, their toys or whatever they was playing with. And, you know, I had certain days I did things. Now, I mean, if I don't want to do it through the day, it'll be there tomorrow waiting for me." The perception they conveyed was that they were more relaxed about parenting.

Grandparents talked about the activities that they engage in for themselves. Examples that were given were "getting out of the house", bubble baths, "give myself a 
talking to", music with headphones, watching television, having a cup of tea, spending time with a spouse, walking, and prayer. Most grandparents acknowledged a need to have personal time to prevent depression. Prayer and faith were used to cope with stress by many grandparents. Several said they lived by tenets such as "one day at a time", "this too shall pass", and "I can do all things through Christ who strengthens me." A coping strategy that was identified by the PI but not explicitly stated was advocacy. The grandparents were very willing to make suggestions of resources to other grandparents and to encourage them to be strong in adversarial situations. This was illustrated by one grandparent providing advice to the grandparent in crisis who said, "Now listen here. You are woman, hear you roar, and you just become a lion and you just say 'come on lady.' That's what I did."

In addition, some grandparents discussed coping strategies they used that were unhealthy or could become unhealthy. A few grandparents talked about having an alcoholic beverage each night, such as a glass of sangria or bourbon. These grandparents discussed that alcohol might not be the best coping strategy but felt it was acceptable in moderation. One grandparent did acknowledge that if she lived closer to her best friends, she would go to "happy hour" more often and that alcohol use would be a problem. Two grandparents discussed smoking. One grandparent had quit smoking recently from being a $2 \frac{1}{2}$ pack-a-day smoker and stated "I had tried quitting before. Nothing ever worked.

The kids came in and they ganged up on me. And, honestly, I don't know what it was but it clicked this time." The other grandparent was "in the process" of quitting but stated that she had cut back to 10 per day. Some grandparents also talked about keeping their feelings in and not talking about it. They perceived that this was unhealthy. The final area that the grandparents discussed was their use of formal and informal social supports.

\section{"Informal Supports: A Necessity"}

When grandparents discussed the types of social supports used, the primary topic of conversation was the informal supports used such as family, friends, online grandparent support groups, and church members. However, formal social supports were utilized by most grandparents with some limitations. Grandparents relied on Social Services and Family Resource Centers for obtaining resources for the grandchildren and access to programs such as Medicaid, Temporary Assistance for Needy Families (TANF), Kinship Care Program, Pennyroyal Mental Health Services, and Pennyrile Area Development District (PADD). However, several grandparents perceived that Social Services did not always provide accurate information or was not well informed about services and legal issues affecting custodial grandparents. This was illustrated when a custodial grandparent stated, "But no one, the left hand never seems to know what the right hand is doing. And, when you bring something up, they'll say, 'really?'". Several of the grandparents felt that services for grandparents raising grandchildren were limited in their rural area. Grandparents Raising Grandchildren Support Groups provide both formal and informal social support. Formal support is provided as the program offers education on various topics to benefit grandparents and grandchildren such as college assistance and legal issues. Informal support is provided by creating access that allows 
custodial grandparents to connect with each other and share experiences. However, some grandparents in this study did not know about the grandparent support groups in the Pennyrile Area. Some grandparents also did not know about community service organizations that provide items such as food and clothing assistance for persons in need.

Informal supports were perceived as key for assisting custodial grandparents dayto-day. For some grandparents, this was an occasional trip to meet with friends or strictly telephone contact as described by a grandparent who said, "Yeah, if you're lucky enough to have a support group or friends in the area that you're at. I'm a California girl. I've none here. So, it's on the phone all the time." Most grandparents talked about having a close friend that they could talk to for support, although some grandparents did not have a trusted friend to share with. One grandparent discussed the challenges of having a grandchild with Type I Diabetes and how most people were afraid of her. This prevented the teenage grandchild from participating in many overnight activities, which would allow respite for the grandparent. However, the grandparent stated, "And she only has one friend, so I don't get, you know, to be away from her, um, except now, she has a boyfriend whose mother has Type I and he has Type I. And, they're in our church and that has been the biggest blessing for me because, they, I'll have a whole Saturday, cause she's gone off with them somewhere." Respite time did not seem as important for other grandparents, as illustrated by a grandparent who said, "She's always gone, you know, we go out [to dinner] with our friends on Friday night and she's always gone with us. So, we just continue to do that." Another grandparent stated, "He goes with us wherever we go." These comments also inferred that the grandparents placed importance on including grandchildren in their social activities. Grandparents were also eager to provide support for each other in the focus groups. If they sensed a need or lack of knowledge for another grandparent, they were quick to offer encouragement and share their knowledge of resources and community assistance.

The majority of the grandparents, even the grandparents who participate in a support group, had limited knowledge about resources in their area. Unsurprisingly, this was particularly true for newer custodial grandparents. However, even grandparents with custody for two years or longer were not aware of many local, state, and federal resources mentioned by other grandparents in the focus group. One grandparent who perceived that local resources were limited stated, "They're probably there, but no one's aware of them. And no one willing gives you any information. We need a navigator, a person who knows, who's aware, who knows, who can inform. We don't have that."

In summary, five themes emerged from the qualitative data and highlight the rural-dwelling custodial grandparents' perceptions of raising grandchildren. Depression and stress were seen as problematic for the majority of grandparents. However, physical health, even with current medical problems, was not viewed to be a deterrent in raising their grandchildren. Talking to others, taking time for themselves, and the use of informal supports were the most important factors in maintaining their mental health. In the next section, the quantitative and qualitative data will be integrated. 


\section{Quantitative and Qualitative Integration}

After the data analysis is completed, mixed methods research involves integrating the quantitative and qualitative data so that a coherent whole emerges and inferences can be made (Creswell \& Plano Clark, 2011). Table 4-10 summarizes the themes and instrument scores. The instrument scores are listed under the qualitative theme that they correspond with, such as the Center for Epidemiologic Studies for Depression (CES-D) score listed under "Mental Health: I Need 'Me' Time." The focus groups had seven participants, combined, while 21 custodial grandparents completed the questionnaires.

The grandparents' perception that physical health was not a problem for them is not supported by their Short Form-36 version 2 (SF-36v2) scores. While the Physical Component Summary score is below average, it includes not only physical functioning but also frequent tiredness, social and role activities, and self-rated health. Since many grandparents explained that depression, stress, and isolation could be problematic for them, this score may reflect limitations when all of these areas are incorporated. In addition, most of the grandparents talked about staying as active as possible for the grandchildren, which may indicate a willingness to downplay their physical limitations for a desire to sustain their involvement with their grandchildren.

Mental health, specifically depressive symptoms, was discussed by most study grandparents as being occasionally problematic. The SF-36v2 mental component summary scale score was average for this study sample. However, it was just within the low end of average. Two of the mental health subscales (Social Functioning and Role Emotional) were below average and the other two mental health subscales (Vitality and Mental Health) were just above the lower average threshold but below the norm average score of 50. The below average scores for Social Functioning and Role Emotional seem to reflect the grandparents' perceptions that their emotional problems interfere some with their social functioning ("No one to talk to that understands") and cause them to have decreased time doing activities they like ("I just have to get out of the house"). The mean CES-D score for this study sample is under the level that would indicate risk of clinical depression. However, the score is reflective of a moment in time for the grandparents and, for the group overall, it did not indicate a risk for clinical depression at that moment. The qualitative results indicate that depression is perceived to be a problematic issue of concern to grandparents.

Stress is the factor that was interwoven throughout the focus group discussions as having the biggest impact on grandparent health. The mean Parenting Stress Index/Short Form (PSI/SF) score does not reflect this. The mean score for the study sample is well below the $90^{\text {th }}$ percentile that would indicate significant levels of stress. However, the stressors that the study grandparents perceived as the biggest problem, conflict with the grandchildren's parents and financial/legal concerns, are not measured by the PSI/SF. Therefore, the mean PSI/SF score may not be reflective of the actual primary stressors faced by custodial grandparents. 
Table 4-10. Integration of Quantitative and Qualitative Data Analysis Results for Rural-dwelling Grandparents Raising Grandchildren in Western Kentucky

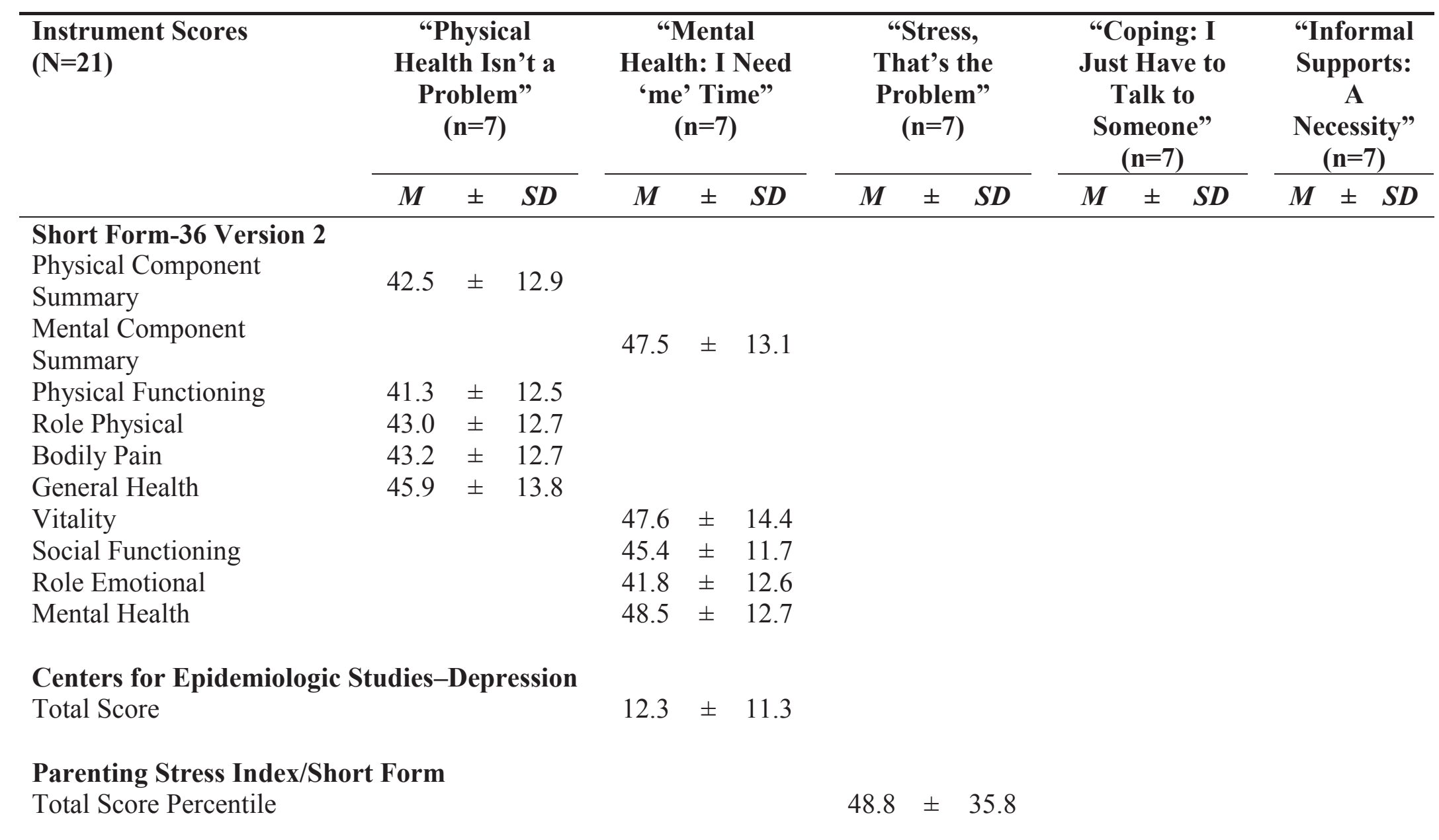


Table 4-10. Continued

\begin{tabular}{|c|c|c|c|c|c|c|c|c|c|c|c|c|c|c|}
\hline \multirow[t]{2}{*}{$\begin{array}{l}\text { Instrument Scores } \\
(\mathrm{N}=21)\end{array}$} & \multicolumn{3}{|c|}{$\begin{array}{c}\text { "Physical } \\
\text { Health Isn't } \\
\text { a Problem" } \\
(n=7)\end{array}$} & \multicolumn{3}{|c|}{$\begin{array}{c}\text { "Mental } \\
\text { Health: I } \\
\text { need 'me' } \\
\text { time" }(\mathrm{n}=7)\end{array}$} & \multicolumn{3}{|c|}{$\begin{array}{c}\text { "Stress, } \\
\text { That's the } \\
\text { Problem" } \\
(n=7)\end{array}$} & \multicolumn{3}{|c|}{$\begin{array}{c}\text { "Coping: I } \\
\text { Just Have to } \\
\text { Talk to } \\
\text { Someone" } \\
(n=7)\end{array}$} & \multicolumn{2}{|c|}{$\begin{array}{c}\text { "Informal } \\
\text { Supports: A } \\
\text { Necessity" } \\
(n=7)\end{array}$} \\
\hline & $M$ & \pm & $S D$ & $M$ & \pm & $S D$ & $M$ & \pm & $S D$ & $M$ & \pm & $S D$ & $M$ & $\pm S D$ \\
\hline \multicolumn{15}{|c|}{ Ways of Coping Questionnaire } \\
\hline $\begin{array}{l}\text { Confrontive Coping Raw } \\
\text { Score }\end{array}$ & & & & & & & & & & 6.6 & \pm & 3.0 & & \\
\hline Distancing Raw Score & & & & & & & & & & 6.3 & \pm & 4.1 & & \\
\hline $\begin{array}{l}\text { Self-controlling Raw } \\
\text { Score }\end{array}$ & & & & & & & & & & 9.4 & \pm & 4.3 & & \\
\hline $\begin{array}{l}\text { Seeking Social Support } \\
\text { Raw Score }\end{array}$ & & & & & & & & & & 6.4 & \pm & 4.1 & & \\
\hline $\begin{array}{l}\text { Accepting Responsibility } \\
\text { Raw Score }\end{array}$ & & & & & & & & & & 3.8 & \pm & 1.9 & & \\
\hline $\begin{array}{l}\text { Escape-Avoidance Raw } \\
\text { Score }\end{array}$ & & & & & & & & & & 5.6 & \pm & 4.0 & & \\
\hline $\begin{array}{l}\text { Planful Problem Solving } \\
\text { Raw Score }\end{array}$ & & & & & & & & & & 10.1 & \pm & 3.0 & & \\
\hline $\begin{array}{l}\text { Positive Reappraisal Raw } \\
\text { Score }\end{array}$ & & & & & & & & & & 10.3 & \pm & 4.3 & & \\
\hline Family Support Scale & & & & & & & & & & & & & & \\
\hline Total Support Score & & & & & & & & & & & & & 30.2 & \pm 11.8 \\
\hline
\end{tabular}


Coping mechanisms were another factor that generated a great deal of grandparent discussion. The mean scores of the Ways of Coping Questionnaire (WCQ) subscales indicate that the top three coping mechanisms for the study sample were selfcontrolling, planful problem solving, and positive reappraisal. Self-controlling coping strategies are efforts to regulate one's feelings and actions. The focus group grandparents gave examples of coping with stress that reflect this strategy such as "giving myself a talking to", going for a walk, or taking time for themselves. The Planful Problem Solving coping strategy is deliberate efforts to alter the situation, including a systematic approach to problem solving. This coping strategy is evident when grandparents discussed their efforts in gaining custody of their grandchildren, developing visitation plans for the grandchildren's parents, and accessing resources. The final coping strategy used most often by this study's sample was positive reappraisal, which endeavors to create positive meaning by focusing on personal growth. The study sample discussed use of family counseling services, more relaxed parenting, and gaining knowledge of custodial grandparent issues.

Finally, social support was perceived by the study grandparents as a vital need for coping with their situation. However, they lacked knowledge about available resources, how to access them, and regulations concerning grandparent rights. Several grandparents also conveyed they felt isolated in their experience and had no one to confide in about their situation. This appears to be reflected in the study sample's mean total support score on the Family Support Scale, which was low indicating little formal or informal support. 


\section{CHAPTER 5. DISCUSSION AND IMPLICATIONS}

This study investigated the physical and mental health, stressors, coping, and social support reported by 21 rural-dwelling grandparents raising their grandchildren in Western Kentucky. Study results provided a description of a) custodial grandparents' health; b) the relationships among factors influencing their health; and c) their perceptions of how stressors, coping, and social support affect their health. This chapter provides an in-depth discussion of the study findings as they relate to previous grandparent raising grandparent research. This chapter will also include an examination of study limitations and implications for future research focused on rural custodial grandparents.

\section{Demographic Characteristics}

The first specific aim of this study was to describe the characteristics of ruraldwelling grandparents raising their grandchildren. Most grandparents in this study were female which is similar to previous grandparent raising grandchildren research. Numerous researchers have focused solely on grandmothers as they are typically the primary caregiver for grandchildren (Bigbee, Musil, et al., 2011; Kelley et al., 2007; Kelley et al., 2010; Musil et al., 2009). Few studies have included grandfathers (Kropf \& Robinson, 2004; Leder et al., 2007; Linsk \& Mason, 2004) and most of these studies have included small samples as did the current study. Only one published study has been conducted to examine the role of custodial grandfathers (Bullock, 2007).

The grandparents in this study had a mean age of 59.8 years $(S D \pm 8.7)$. This is congruent with samples described in previous grandparent raising grandchildren research as grandparents in these studies typically reported a mean age of 48-60 years (Bigbee, Musil, et al., 2011; Kelley et al., 2010; Leder et al., 2007). Marital and employment status in these studies has been varied although the influence of these variables on custodial grandparents has been understudied. The number of grandchildren being raised by custodial grandparents has also varied in previous grandparent research and has not been a focal point for any study. In the current study, most participants cared for one grandchild.

While the sample for the current study was primarily Caucasian $(85.7 \%)$, other investigators have focused on ethnically mixed samples of African American and Caucasian (Leder et al., 2007; Musil et al., 2009) or only on African American grandparents (Kelley et al., 2007; Trail Ross \& Aday, 2006). Grandparents raising grandchildren research is sparse for other ethnicities. Our sample was very similar to the ethnic mix of custodial grandparents in Kentucky, which in 2012 was $87 \%$ Caucasian and 10\% African American (Grandfactsheets.org, n. d.). Two recent studies have been conducted on rural-dwelling custodial grandparents. One study in frontier Idaho had all Caucasian participants (Bigbee, Boegh, et al., 2011) and the other, a rural-urban 
comparison with Ohio grandmothers, had a predominantly Caucasian sample particularly for the rural sample (Bigbee, Musil, et al., 2011).

Type of insurance has not been a component of previous custodial grandparent research. However, health disparities are a long-standing concern for rural residents, which includes a lack of insurance and decreased availability of healthcare providers (Agency for Healthcare Research and Quality [AHRQ], 2009; Hart, Salsberg, Phillips, \& Lishner, 2002). For this reason, information on the availability of health insurance and healthcare providers was obtained from the custodial grandparents in this study to determine their degree of difficulty in accessing healthcare. Most grandparents denied difficulty accessing healthcare in their towns and were satisfied with the quality of the services, although some custodial grandparents required specialist care that necessitated travel to larger cities. Grandparents' perceptions were that basic medical care was available in their area but, for more serious health problems, they need to go to a larger city, as illustrated by a grandparent who said, "Lourdes or Western Baptist [in Paducah, KY], you know, I mean if you really got something, then you need to go on up there." For grandparents that are poor or do not have transportation, the necessity of travel would bar access to this higher level of care and precipitate a more rapid health decline. This study's findings highlight the potential for health disparities among rural custodial grandparents.

Information was also obtained on custodial grandparents' current health problems to determine their risk for declining health. Hypertension, diabetes, and obesity are common health problems noted in previous custodial grandparent studies (Bigbee, Boegh, et al., 2011; Dowdell, 2005) and are congruent with the findings of this current study. These medical conditions are manageable with appropriate healthcare but if a rural custodial grandparent experiences healthcare disparities, these medical conditions have high rates of complications. Since there is little research about rural custodial grandparents, future studies are needed to determine the extent that healthcare disparities effect this population. In this study, reasons that grandparents have custody of grandchildren were similar to previous custodial grandparent research, with parental substance abuse being the most common reason (Dowdell, 2005; Trail Ross \& Aday, 2006).

\section{Physical and Mental Health, Stressors, Coping, and Social Support}

Specific aim two of this study was to describe the physical and mental health, stressors, coping, and social support of rural-dwelling custodial grandparents.

\section{Physical Health}

The grandparents in this study were below average in their mean SF36v2 subscale scores for physical functioning, role physical, bodily pain, and general health, which indicated that grandparents had some limitations in these areas. Few authors have 
consistently used the SF36 as a measure of physical health in custodial grandparents, (Bigbee, Boegh, et al., 2011; Bigbee, Musil, et al., 2011; Kelley et al., 2007; Kelley et al., 2000; Kelley et al., 2010; Kelley, Yorker, Whitley, \& Sipe, 2001; Whitley et al., 2001) which would enable comparisons to be made between studies. However, there are limitations in making direct comparisons about physical health between these studies because of historical changes in SF36 scoring methods and interpretation.

Previously, the SF36 scores underwent linear transformation to yield a score 0100 and the scores received were compared to general population norms to determine an individual's functional level. Currently, the scoring software for the SF36v2 has been updated to calculate scores using norm-based scoring that factors in population norms so interpretation is simplified (Maruish, 2011). In studies of urban grandparents by Kelley, Whitely, et al (2007; 2000; 2010; 2001; 2001), the SF36 Physical Functioning subscale was, most commonly, the only measure of physical health that was used. In all of these studies, grandparents were found to have moderate interference in their physical health, which is somewhat better than the below average grandparent physical health in this study.

In two previous studies on rural custodial grandparents, norm-based scoring appears to have been used for SF36 data (Bigbee, Boegh, et al., 2011; Bigbee, Musil, et al., 2011). In both of these studies, the only SF36 scores reported for physical health were those for the physical component summary scale. The first study was a rural-urban comparison of custodial grandparents. Both groups had mean physical component summary scores below average, with a rural score of 43.5 and an urban score of 42.9 (Bigbee, Musil, et al., 2011). In the second rural custodial grandparent study, focusing on frontier Idaho grandparents, the physical component summary score was 43.45 preintervention and 42.81 post-intervention (Bigbee, Boegh, et al., 2011). The current study had similar findings to both of these previous studies with a mean physical component summary score of $42.5(S D \pm 12.9)$ for the study sample. These results indicate that physical health was a concern for participating custodial grandparents.

\section{Mental Health}

In this study, mental health functioning was found to be on the lower end of average. In custodial grandparent research, few researchers have used the SF36 as a measure of mental health functioning but many have used the CES-D. For researchers that have used the SF36 previously, there are scoring concerns relative to historical changes in the scoring methods and interpretations of this subscale. Despite the SF36 changes, the interpretation of the SF36 scores in previous studies indicate average mental health functioning for custodial grandparents (Bigbee, Boegh, et al., 2011; Bigbee, Musil, et al., 2011; Kelley et al., 2010; Whitley et al., 2001). Mean mental component summary score for the current study of $47.5( \pm 13.1)$ is just slightly below the mental component summary scores in previous rural custodial grandparent studies. However, all of these study findings reflect scores in the average range for mental health functioning. 
The CES-D is another measure widely used for measuring mental health in custodial grandparents. In these studies, mean CES-D scores for custodial grandparents have ranged 11.5 to 17.6 (Fuller-Thomson \& Minkler, 2000; Linsk et al., 2009; Minkler et al., 1997; Musil, 2000; Musil et al., 2009). In the current study, the mean CES-D score was $12.3( \pm 11.3)$, which is below the level of 16 or higher that indicates a risk for depression. In a comparison study of rural-urban grandparents raising grandchildren, the mean CES-D scores were slightly higher, with mean scores of 13.5 for urban grandparents and 12.9 for rural grandparents (Bigbee, Musil, et al., 2011). Grandparents in both studies had scores that reflect a low risk for depression.

While mean CES-D scores in many of these studies do not reflect a high risk of depression, the context in which the custodial grandparent is raising the grandchildren seems to influence depression scores. The CES-D scores in the current study ranged from 0 to 43. The highest score belonged to a grandmother with informal custody of three grandchildren who reported current crises in several different areas of her life. Other high scores belonged to custodial grandparents who were also caregivers for disabled spouses, had recently obtained custody of their grandchild, or had limited financial resources. Custodial grandparents with the lowest scores reported adequate financial resources and support systems on the study questionnaires and during focus group discussions.

\section{Stressors}

The Parenting Stress Index, short form (PSI/SF) was used to measure grandparent stress in this study. A mean total stress percentile score of $48.8(S D \pm 35.8)$ was obtained for this study sample, which does not indicate significant levels of stress. The normative range for total stress percentile scores is within the $15^{\text {th }}$ to $85^{\text {th }}$ percentile (Abidin, 1995). The PSI/SF has been used in few previous custodial grandparent studies (Butler \& Zakari, 2005; Leder et al., 2007; Musil, 2000; Musil et al., 2002; Trail Ross \& Aday, 2006). However, comparison of scores across studies and with this study is difficult because either a) scores are not reported in the articles, b) only raw scores are provided with insufficient information to translate them into percentile scores, or c) the full PSI was used. For the current study, custodial grandparent stress, discussed in the focus group interviews, was not because of parent distress, difficult children or difficult parent/child interactions. The reasons for their stress were revealed during the focus group discussions and will be discussed in the qualitative discussion that follows.

\section{Coping}

The Ways of Coping Questionnaire (WCQ) indicates the preferred coping strategy used by individuals. In the current study sample, the most preferred coping strategies were positive reappraisal, planful problem solving, and self-controlling with mean scores of $10.3(S D \pm 4.3), 10.1(S D \pm 3.0)$, and $9.4(S D \pm 4.3)$, respectively. Trail Ross and Aday (2006) reported that custodial grandparents preferred seeking social 
support and positive reappraisal as their coping strategies. A few researchers have used the WCQ in grandparent raising grandchildren studies (Musil, 2000; Musil \& Ahmad, 2002; Trail Ross \& Aday, 2006). However, investigators used two different modified versions of the questionnaire making cross-study comparisons of mean scores difficult. Future research with standardized coping instruments is needed to determine coping preferences for custodial grandparents.

\section{Social Support}

The Family Support Scale (FSS) measures the helpfulness of different supports that may be available for an individual. In this study, the group's mean total support score on the FSS was $30.2(S D \pm 11.8)$. This indicates lower levels of support as the scores can range 0-95, with higher scores indicating higher levels of support. The FSS has been used by other researchers in grandparents raising grandchildren research (Kelley et al., 2007; Kelley et al., 2000; Kelley et al., 2001; Leder et al., 2007). An intervention study about urban African American custodial grandmothers yielded mean FSS scores of 26.25 pre-test and 30.12 post-test (Kelley et al., 2007). In this study, the intervention included case management services and grandparent support groups which contributed to a significant increase in the grandparents' FSS scores. A second urban custodial grandparent intervention study produced mean FSS scores of 27.21 ( $S D \pm 11.04)$ pre-test and $34.63(S D \pm 17.3)$ post-test, which was a significant improvement after the intervention (Kelley et al., 2001). This intervention study also included social worker case management and grandparent support group attendance. Finally, in another study examining the effects of social support and resources on psychological distress, the researchers obtained an FSS mean of 25.9 for their study sample (Kelley et al., 2000). All of these studies indicate that the FSS mean score for this study, while low, are common for custodial grandparents. This finding indicates the difficult situation that custodial grandparents experience and the potential isolation that can occur when they are raising their grandchildren.

\section{Relationships among Health, Stressors, Coping, and Social Support}

The third specific aim of this study was to examine the relationships among physical and mental health, stressors, coping, and social support for rural-dwelling custodial grandparents. Several significant correlations were found between the study variables. One of the relationships noted in this study was between depression and physical and mental health, where higher levels of depression resulted in poorer physical and mental health. This relationship was also found in a study of urban grandparents where a moderately significant negative correlation $(r=-.39, p<.001)$ was found between depression and physical health (Kelley et al., 2000). While this relationship is not surprising, it raises concern since the grandparents in this study talked about a tendency for depression at different points in time. Depression combined with their already below average physical health could impair them even more, potentially impacting their ability to care for their grandchildren. 
Another relationship noted in this study was between stress and the measures for mental health and depression. Moderate negative correlations were significant between the PSI/SF and the SF36 mental component summary scale, Vitality subscale, Social Functioning subscale, Role-emotional subscale, and Mental Health subscale. This suggests that the more stress a grandparent is under, the more mental health limitations the grandparent will have. There was also a significant positive correlation between the PSI/SF and the CES-D score indicating increased stress results in increased depression. Other studies have corroborated this finding as well noting significant negative relationships between parenting stress and physical and mental health functioning $(r=$ -.424 to $-.776, p<.05)$, which indicates increased stress leads to poorer physical and mental health (Leder et al., 2007). Musil (2000) also found a highly significant positive correlation $(r=.60, p<.001)$ between stress and depression in a study of urban grandparents. Musil also noted a small significant correlation $(r=.31, p<.01)$ between stress and self-assessed health. These findings are also concerning for this study's grandparents because of their perceived tendency toward depression and having stress perceived to be their main problem.

The WCQ coping strategies were found to be significantly correlated with a few areas. Interestingly, the top three coping strategies (positive reappraisal, planful problem solving, and self-controlling) preferred by grandparents in this study were not significantly correlated with physical or mental health, stress, or social support with one exception. The self-controlling coping strategy had a significant negative correlation with the SF36v2 General Health subscale $(r=-.46, p<.05)$. The lowest scoring coping strategies, accepting responsibility and escape avoidance, had significant negative correlations $(r=-.44$ to $-.76, p<.05)$ with all of the mental health subscales on the SF36. This implies that the more these two coping strategies are used the more mental health limitations grandparents will have. The escape-avoidance coping strategy also had a significant moderate correlation $(r=.52, p<.05)$ with parenting stress. The results of this study are different than findings by Trail Ross and Aday (2006). In their study using the WCQ, five of the coping strategies (positive reappraisal, accepting responsibility, confrontive coping, self-controlling, and distancing) were significantly correlated with lower perceived stress. Musil (2000) also noted significant correlations between avoidant $(r=.57, p<.001)$ and minimizing $(r=.40, p<.001)$ coping strategies and depression, indicating that the more these strategies are used, the more depression the grandparent will have. Since there are different study outcomes and many different coping measures used in custodial grandparent research, it is challenging to synthesize the impact of coping strategies for rural grandparents.

Finally, the FSS had significant positive correlations $(r=.48$ to $.70, p<.05)$ with all of the SF36 physical and mental health scales and subscales. This indicates that increased levels of social support for custodial grandparents will result in better physical and mental health. This finding has been duplicated in numerous studies (Dowdell, 2005; Gerard et al., 2006; Hughes et al., 2007; Kelley et al., 2000; Leder et al., 2007; Musil, 2000; Musil et al., 2009). However, some of the rural grandparents in this study perceived that formal and informal social supports were scare. Some reasons for this lack of support could be being overwhelmed with multiple caregiving roles, unaware of 
support services, lack of transportation, and a mistrust of official agencies. Also, some grandparents voiced a concern that if they sought government aid, the agency would notify the biological parent of the grandchild's whereabouts. Some grandparents were reluctant to have an incarcerated biological parent aware of the grandchild's location for safety reasons.

\section{Grandparents' Perceptions}

The fourth specific aim of this study focused on the custodial grandparents' perceptions of the effects stressors, coping, and social support had on their physical and mental health. Even though the SF36v2 results indicated below average physical functioning, the grandparents in the focus groups did not perceive that physical health was a limitation for them. This is evident in comments such as one made by a 73 year old grandmother, "I can't run when I play kickball. I mean, they usually get me out because I can't run fast or there's things I can't do." Another example was a conversation by several grandmothers, who were 64 years and the 73 year old. They discussed going to Venture River (local waterpark): one grandmother said, "We put our bathing suits on and go" while the other said, "I finally just said forget it, if they don't want to look at me, they don't have to look." While grandparents talked about stress increasing and decreasing over time, the stress was never completely absent for them. Some grandparents talked about ways they had found to cope with stress and for most, it involved taking time for their own interests or respite. Even though the SF36v2 mental health measures and CES-D results indicated the grandparents' mental health functioning was average, most talked about depression being a problem at times. Custodial grandparents who had social support described at length the importance of having social support, particularly someone to talk with. For many, formal social support, in the way of financial and legal assistance and Family Social Services for custodial issues, were vital to the grandparents as well.

Custodial grandparents' perceptions, like the ones in this study, have been noted in other grandparents raising grandchildren studies (Dowdell, 2004; Dowdell, 2005). Custodial grandparents report that they love their support group because it lets them know they are not alone (Dowdell, 2004). A source of stress noted by other studies is conflict with the birth parent (Butler \& Zakari, 2005), which was a thread throughout focus groups in the current study. This was particularly true if the grandchildren were placed with the grandparents because of drug/alcohol abuse or child neglect. Another relationship stressor described by some grandparents in this study was manipulation of the grandparent and grandchildren by the birth parent. This grandparent stressor was also noted in a study by Waldrop and Weber (2001) as well as other frequent stressors, including financial and legal issues. These stressors were perceived by the grandparents in the current study as an important concern for them. The results of the current study provide insight into the health of rural grandparents raising grandchildren. The findings, overall, appear similar to those described in most published custodial grandparent studies. However, this is the first study to use a mixed methods approach to examine physical and mental health, stress, coping, and social support for custodial grandparents. This unique 
approach provides in-depth information about the physical and mental health, stress, coping and social support of custodial grandparents from a quantitative and qualitative approach. Additionally, the focus group discussions provide a comprehensive examination of the issues faced by rural grandparents raising grandchildren. Nevertheless, there are some limitations to note with this study.

\section{Limitations and Strengths}

There are several limitations and strengths for this study. Limitations include sample size and characteristics, recruitment difficulties, and study design and instrumentation challenges. Strengths include the use of a comprehensive mixed methods approach, standardized instruments, and information collected about the needs of rural grandparents raising grandchildren. Limitations are described followed by study strengths.

First, this study's findings are based on a small, homogeneous sample from Western Kentucky. Since this study's participants were all recruited from a rural nine county area of Western Kentucky, the findings are not representative of grandparents in other regions. The study sample was also small making generalization to the larger population of grandparents raising grandchildren premature. The study participants were primarily Caucasian grandparents; therefore ethnic groups are underrepresented in the study sample.

A second limitation in this study was recruitment. While the Principle Investigator (PI) continually learned of grandparents raising grandchildren, they were either not in the geographic recruitment area or were reluctant to participate. The PI's perception was that the grandparents were extremely busy and did not have time for another activity, even though participation would have been brief. These recruitment difficulties may have contributed to selection bias resulting in custodial grandparents with the most physical and mental health limitations choosing not to participate.

A third limitation was the study's cross-sectional design. This study focused on one point in time for the participants, so it provides a snapshot of their experiences. The importance of this limitation is supported by comments from the grandparents about being depressed at different points in time. Also, most of the grandparents were not experiencing significant problems with their chronic health conditions at the time of the data collection. The results could have been very different if their health had not been relatively stable as health challenges alter perceptions and most instruments reflected their perceptions about health, stressors, coping, and social support.

The final limitation in this study was instrumentation. Two of the instruments used in this study would require closer consideration for future custodial grandparent raising grandchildren studies. First, the Parenting Stress Index, Short Form (PSI/SF) scales measure stress caused by parenting, child behavior, and parent-child interactions. In this study, grandparents verbalized that stress was a problem and always present. The 
grandparents' perceptions were that financial and legal problems as well as difficult relationships with the grandchildren's birth parents, not their grandchildren, were their main sources of stress. This finding seemed to be reflected by their mean PSI/SF score, which was within the normal range for parenting stress. Consequently, use of an additional stress measure or a measure that captures global stress would be advisable in future grandparents raising grandchildren research. The other instrument limitation was the Ways of Coping Questionnaire. There has been much debate about the theoretical underpinnings of coping instruments used in research today (Endler \& Parker, 1990; Schwarzer \& Schwarzer, 1996). There are two main theoretical problems found with coping instruments (Schwarzer \& Schwarzer, 1996). One is that cognitive coping and cognitive appraisal can be confounded. This confounding occurs when an individual begins with cognitive appraisal of a situation, which then results in cognitive coping. The other theoretical problem is a difficulty separating coping from coping resources. While these problems exist with the WCQ as well, this instrument is still considered the "gold standard" for measuring coping. Nevertheless, a recommendation for future studies would be to explore alternate coping measures for use with grandparents raising grandchildren. Finally, while all of the instruments in this study have been used in previous grandparents raising grandchildren research, there is a dearth of reliability and validity information on the instruments use with a rural population. This lack of psychometric information can raise questions about the results when this information is unavailable.

There are several strengths for this study. First, this is the first study of rural grandparents raising grandchildren that provides the richness of a mixed methods approach. While two published studies have been conducted with rural grandparents (Bigbee, Boegh, et al., 2011; Bigbee, Musil, et al., 2011), these studies did not explore the grandparents' perceptions. This depth of data can help tease out the most important issues for rural grandparents and guide future research and intervention tailored to their needs.

Second, the findings of this study highlight the unique needs of rural grandparents. Since this is an understudied population, this study will provide insight into the challenges rural grandparents face and the resources they need. Some needs were congruent with needs reported by urban grandmothers, for example, financial issues and requiring assistance to make ends meet. Others, like lack of public transportation to get to area services, are unique to a rural population. Rural grandparents need ways to connect with other custodial grandparents, particularly when transportation is an issue. While most of the grandparents in this study perceived their area healthcare as adequate, there is still concern due to a lack of specialists. For a rural grandparent to see a healthcare specialist, i.e. endocrinologist, he or she would have to travel over an hour to a large urban medical center. For some grandparents, this would present an enormous hardship. Transportation issues and lack of specialty healthcare could place rural grandparents at increased risk of declines in physical and mental health when they are already below average to average. 
The final strength for this study was the use of standardized instruments. All of the instruments used in this study have been used in previous grandparents raising grandchildren research. This is particularly true for the SF-36 General Health Survey, which is a common measure in these studies. Use of standardized instruments facilitates comparison across studies so that more complete information can be garnered about grandparents raising grandchildren. The use of consistent measures will also increase the reliability and validity information for the use of these instruments with all types of custodial grandparents.

\section{Practice and Policy Implications}

There are a few implications for practice and policy that require discussion. In practice settings, healthcare providers need to determine if an older patient is a grandparent raising grandchildren. Rural grandparents may be reluctant to openly share this fact with anyone, including healthcare professionals, due to values of independence, self-reliance, and privacy and a distrust of "outsiders" (Bigbee \& Lind, 2007). Grandparents may also be reluctant to disclose their caregiver status when health problems arise because of fear the grandchildren will be removed from their home. Healthcare providers need to routinely ask older patients if they are a caregiver for grandchildren or an ill loved one. Since the findings in this study indicate that rural grandparents are below average for their physical health and low average for their mental health, healthcare professionals must assess rural grandparents for further declines in health and increasing levels of stress then provide support and resource referrals as indicated.

Policy implications center on a need to increase access to social support for rural grandparents. While there are grandparent support groups in this area of Kentucky, some of the grandparents in this study were not aware of them. They also had limited knowledge of resources they could access in their area. Greater efforts need to be made to publicize information about available grandparent resources and support groups. In addition, for this study sample, travel assistance and child care arrangements would enable rural grandparents to attend as public transportation options are virtually nonexistent. Transportation assistance could possibly be coordinated through church outreach efforts, utilizing church vans to provide transportation to monthly grandparent support groups for those in need. Also, rural grandparents could benefit from a "navigator", as suggested by one of this study's grandparents. Many grandparents are overwhelmed by their situation and tackling a complex social service system is more than they can manage. This would be a person knowledgeable in available resources within states and communities that could provide rural grandparents with reliable information. Developing relationships with people in their community is important for rural residents and a "navigator" could be that trusted community individual for custodial grandparents getting information. 


\section{Theoretical Implications}

An additional strength of this study is the support it provides for the Stress Process Model. Certain background and context issues for rural grandparents in this study affected the stress they experienced. Several grandparents discussed stress caused by relationship difficulties they had with their spouse related to childrearing beliefs and with their adult children over grandchild custody issues. For many participants, finances were a concern since most of the study grandparents were unemployed, which included being retired and on a fixed income. A few of the study grandparents also discussed being a caregiver for other disabled family members as well as their grandchildren. This intergenerational caregiving compounds the stressors they experience in the caregiver role. The final contextual issue for this sample of rural grandparents was limited social resource availability. While there are services available in the study area, many grandparents did not have knowledge of them or how to access them. Time constraints, misinformation, and transportation were also barriers to accessing social services for some of the grandparents.

Stressors are a second domain in the Stress Process Model, which includes primary and secondary stressors. Primary stressors are problematic conditions for caregivers, such as dependency of the care recipient, behavioral problems, and relationship changes (Pearlin et al., 1990). According to grandparents in the current study, the grandchildren's needs and behaviors were not their main source of stress. However, some did discuss increased relationship strife within the home when they had teenage grandchildren beginning to express their independence. Although dependence of the grandchildren did not appear to be perceived as a stressor by the grandparents, it was inferred in their discussion. Providing for their grandchildren's needs was an evident concern as they discussed a need for resources and shared resource information with each other. The information they shared and needed were things that let them provide for the grandchildren, i.e. Medicaid, Temporary Assistance for Needy Families (TANF), food, utility bill assistance, Kinship Care Program access, clothing, and school supplies.

Primary stressors lead to two types of secondary stressors: role strains and intrapsychic strains. The three types of role strains discovered in the grandparents' discussions were family conflict, economic problems, and constriction of social life. The presence of family conflict as a secondary stressor was evident when grandparents discussed the relationship difficulties they have or have had with the grandchildren's birth parents. A few grandparents also discussed relationship difficulties with their other adult children who disagreed with the grandparents having custody of a sibling's children. For some of the grandparents, family conflict was ongoing. As previously discussed, grandparents had financial issues that affected their daily lives as evidence of economic problems. For many of the study grandparents, if they participated in any social activities, they did things that their grandchildren could do with them. This creates barriers to doing age appropriate activities with other older adults that do not have young children to care for. However, the grandparents conveyed that their social life was not as important as caring for their grandchildren. There are two components of intrapsychic strains that emerged from the data: gain and role captivity. Gain was exemplified in the 
grandparents' apparent fondness and love for their grandchildren. During discussions, they bragged about their grandchildren's achievements, going to college, and emotional adjustment. Many had strong faith and expressed that God had placed them there for the grandchildren. However, despite this commitment to raising their grandchildren, a few were able to express "I got to be honest with you, I'm tired of being a grandparent [raising grandchildren]. It's just tiresome! I don't know, just got to deal with it." This sentiment is an example of role captivity as a stressor for some grandparents.

A third domain of the Stress Process Model is mediators, which includes coping and social support. According to Pearlin, et al (1990), "coping represents behaviors and practices of individuals as they act on their own behalf" (p. 590). In this study, the three preferred coping strategies identified by the WCQ were positive reappraisal, planful problem solving, and self-controlling. While it is difficult to assess the direct impact of coping on stress, research has shown it has indirect effects on mediating stress (Pearlin et al., 1990). That seems to be the situation in this study. While no correlation was found between the three preferred coping strategies and the PSI/SF scores in the quantitative analysis, grandparents demonstrated use of these coping strategies in descriptions of and actions with stressful situations during the focus groups. For example, grandparents were eager to a) share resources with each other as problem-solving efforts; b) discuss how they had experienced personal growth since gaining custody; and c) explain the difference in how they handle family conflict now that they have custody of their grandchildren. Social support is the second mediator described in the Stress Process Model. The grandparents in this study received below average social support scores on the FSS. Again, it can be difficult to determine the direct impact of social supports on stress levels, but there are indirect effects as well. In this study, both the quantitative and qualitative results support low levels of support for this group of grandparents, which may explain their perception of constant stress levels.

The final domain of the Stress Process Model is outcomes. According to Pearlin et al. (1990), "outcomes... involve the well-being of people, their physical and mental health, and their ability to sustain themselves in their social roles" (p. 590). The grandparents in this study had below average physical health and average mental health. However, it is difficult to know how their health would be, given their age, if they were not raising their grandchildren. On one hand, they are participating in activities they wouldn't ordinarily do, given their age, i.e. kickball. On the other hand, one grandmother stated, "I do have high blood pressure that started when all this started [raising a grandchild]." This conundrum underscores the need for continued research so an understanding of custodial grandparent health can be reached and appropriate interventions designed to support grandparents raising grandchildren.

\section{Recommendations for Future Research}

This study highlights several recommendations for future research with rural grandparents raising grandchildren. While the results of this study seem to be consistent with previous grandparents raising grandchildren research findings, both urban and rural 
grandparents, larger sample sizes are needed to allow generalization. There is a need for longitudinal research with rural grandparents raising grandchildren so better determinations can be made about the relationships of stressors, coping, and social support on their physical and mental health over the course of their career as custodial grandparents. These types of studies would allow researchers to understand the stress process of custodial grandparents and design support services accordingly to improve or maintain grandparent health. Intervention studies have recently been conducted with grandparents raising grandchildren in both urban and rural settings. However, the intervention study with rural grandparents in frontier Idaho only included six families as a demonstration project (Bigbee, Boegh, et al., 2011). Since availability of social support seems to be an issue for rural grandparents, further intervention studies are needed to determine which services are most effective in decreasing stress and preserving grandparents' caregiver status for their grandchildren.

\section{Summary}

The health of rural grandparents raising their grandchildren is a complex phenomenon. Since the number of grandparents raising grandchildren continues to increase, it becomes increasingly important to understand how to support and preserve this important safety net for children who can no longer live with their birth parents. Few investigators have combined physical and mental health, stress, coping, and social support into a single study and those studies have only taken a quantitative approach, and few have focused on rural custodial grandparents. The current study contributes to science because it is one of the first to explore physical and mental health, stress, coping, and social support for custodial rural grandparents using mixed methods. The mixed methods design provided in-depth understanding of issues affecting rural custodial grandparents. Participants in this study reported below average physical health and average mental health. They perceived that physical heath was not a problem, depression was occasionally problematic, but stress was the biggest issue they dealt with constantly. Study results support use of the Stress Process Model as a conceptual framework in rural grandparents raising grandchildren research. Understanding that stress may be prevalent in these caregivers suggests the need for additional research, including intervention trials that will support health and wellbeing in these caregivers who are a valuable resource for children facing the untimely loss of a parent caregiver. 


\section{LIST OF REFERENCES}

Abidin, R. A. (2011). Parenting stress index: Short form (PSI/SF). Retrieved from http://www4.parinc.com/Products/Product.aspx?ProductID=PSI-SF

Abidin, R. R. (1995). Parenting stress index: Professional manual (3rd ed.). Lutz, FL: PAR.

Agency for Healthcare Research and Quality [AHRQ]. (2008). 2008 national healthcare disparities and quality reports. (AHRQ Publication No. 09-0002). Retrieved from http://www.ahrq.gov/qual/nhdr08/nhdr08.pdf

Agency for Healthcare Research and Quality [AHRQ]. (2009). 2009 national healthcare disparities report. (AHRQ Publication No. 10-0004). Retrieved from http://www.ahrq.gov/qual/nhdr09/nhdr09.pdf

American Institute of Stress. (n. d.). Stress, definition of stress, stressor, what is stress? Eustress? Retrieved from http://www.stress.org/topic-definition-stress.htm

Baker, L. A., \& Silverstein, M. (2008). Depressive symptoms among grandparents raising grandchildren: The impact of participation in multiple roles. Journal of Intergenerational Relationships, 6(3), 285-304.

Bigbee, J. L., Boegh, B. V., Prengaman, M., \& Shaklee, H. (2011). Promoting the health of frontier caregiving grandparents: A demonstration project evaluation. Journal for Specialists in Pediatric Nursing, 16(2), 156-161. doi: 10.1111/j.17446155.2011.00284.x

Bigbee, J. L., \& Lind, B. (2007). Methodological challenges in rural and frontier nursing research. Applied Nursing Research, 20(2), 104-106. doi: 10.1016/j.apnr .2007 .01 .001

Bigbee, J. L., Musil, C., \& Kenski, D. (2011). The health of caregiving grandmothers: A rural-urban comparison. The Journal of Rural Health, 27(3), 289-296. doi: $10.1111 / \mathrm{j} .1748-0361.2010 .00340 . \mathrm{x}$

Blustein, J., Chan, S., \& Guanais, F. C. (2004). Elevated depressive symptoms among caregiving grandparents. Health Services Research, 39(6p1), 1671-1690. doi: 10.1111/j.1475-6773.2004.00312.x

Bullock, K. (2004). The changing role of grandparents in rural families: The results of an exploratory study in Southeastern North Carolina. Families in Society: The Journal of Contemporary Human Services, 85(1), 45-54. doi: 10.1606/10443894.258 
Bullock, K. (2007). Grandfathers raising grandchildren: An exploration of African American kinship networks. Journal Of Health \& Social Policy, 22(3-4), 181197.

Burnette, D. (1999). Physical and emotional well-being of custodial grandparents in Latino families. American Journal of Orthopsychiatry, 69(3), 305-318.

Burton, L. M. (1992). Black grandparents rearing grandchildren of drug-addicted parents: Stressors, outcomes, and social service needs. The Gerontologist, 32(6), 744-751.

Butler, F. R., \& Zakari, N. (2005). Grandparents parenting grandchildren: Assessing health status, parental stress, and social supports. Journal of Gerontological Nursing, 31(3), 43-54.

Cox, C. B. (2000). Why grandchildren are going to and staying at grandmother's house and what happens when they get there. In C. B. Cox (Ed.), To grandmother's house we go and stay: Perspectives on custodial grandparents (pp. 3-19). New York, NY: Springer.

Creswell, J. W., \& Plano Clark, V. L. (2011). Designing and conducting mixed methods research (2nd ed.). Los Angeles, CA: SAGE Publications.

Dellman-Jenkins, M., Blankemeyer, M., \& Olesh, M. (2002). Adults in expanded grandparent roles: Considerations for practice, policy, and research. Educational Gerontology, 28(3), 219-235. doi: 10.1080/036012702753542526

Dowdell, E. B. (2004). Grandmother caregivers and caregiver burden. Maternal Child Nursing, 29(5), 299-304.

Dowdell, E. B. (2005). Grandmother caregiver reactions to caring for high-risk grandchildren: "I could write a book!". Journal of Gerontological Nursing, 31(6), 31-37.

Dunst, C. J., Trivette, C. M., \& Jenkins, V. (2007). Family Support Scale: Reliability and validity. Retrieved from http://www.wbpress.com/

Economic Research Service of the U. S. Department of Agriculture. (2007, September 4, 2007). Rural definitions. Retrieved from http://www.ers.usda.gov/Data/RuralDefinitions/

Endler, N. S., \& Parker, J. D. (1990). Multidimensional assessment of coping: A critical evaluation. Journal of Personality and Social Psychology, 58(5), 844-854. doi: 10.1037/0022-3514.58.5.844

Fink, A. M. (2009). Toward a new definition of health disparity. Journal of Transcultural Nursing, 20(4), 349-357. doi: 10.1177/1043659609340802 
Folkman, S., \& Lazarus, R. S. (1980). An analysis of coping in a middle-aged community sample. Journal of Health and Social Behavior, 21(3), 219-239.

Folkman, S., \& Lazarus, R. S. (1988). Ways of coping questionnaire: Sampler set: Manual, test booklet, scoring key. www.mindgarden.com: Consulting Psychologists Press, Inc.

Folkman, S., \& Lazarus, R. S. (n.d.). Ways of coping questionnaire. Retrieved from http://www.mindgarden.com/products/wayss.htm

Fuller-Thomson, E., \& Minkler, M. (2000). African American grandparents raising grandchildren: A national profile of demographic and health characteristics. Health and Social Work, 25(2), 109-118.

Fuller-Thomson, E., \& Minkler, M. (2005). American Indian/Alaskan native grandparents raising grandchildren: Findings from the Census 2000 Supplementary Survey. Social Work, 50(2), 131-139.

Gerard, J. M., Landry-Meyer, L., \& Roe, J. G. (2006). Grandparents raising grandchildren: The role of social support in coping with caregiving challenges. International Journal of Aging and Human Development, 62(4), 359-383.

Goodman, C., \& Silverstein, M. (2002). Grandmothers raising grandchildren: Family structure and well-being in culturally diverse families. Gerontologist, 42(5), 676689.

Goyer, A. (2010). More grandparents raising grandkids: New census data shows an increase in children being raised by extended family. AARP. Retrieved from AARP website: http://www.aarp.org/relationships/grandparenting/info-122010/more grandparents raising grandchildren.html

Grandfactsheets.org. (n.d.). Grandfacts: State fact sheets for grandparents and other relatives raising children: Kentucky. Retrieved from http://www.aarp.org/content/dam/aarp/relationships/friendsfamily/grandfacts/grandfacts-kentucky.pdf

Grinstead, L. N., Leder, S., Jensen, S., \& Bond, L. (2003). Review of research on the health of caregiving grandparents. Journal of Advanced Nursing, 44(3), 318-326.

Hart, L. G., Salsberg, E., Phillips, D. M., \& Lishner, D. M. (2002). Rural health care providers in the United States. The Journal Of Rural Health, 18 Suppl, 211-232.

Hayslip, B., Jr., \& Kaminski, P. L. (2005). Grandparents raising their grandchildren: A review of the literature and suggestions for practice. The Gerontologist, 45(2), 262-269. 
Hughes, M. E., Waite, L. J., LaPierre, T. A., \& Luo, Y. (2007). All in the family: The impact of caring for grandchildren on grandparents' health. Journal of Gerontololgy: Social Sciences, 62(2), S108-119.

Johns, M. (2000). Planning for permanence. In C. B. Cox (Ed.), To grandmother's house we go and stay: Perspectives on custodial grandparents (pp. 149-163). New York, NY: Springer.

Johnson, J., H., Jr., \& Kasarda, J. D. (2011). Six disruptive demographic trends: What census 2010 will reveal. Retrieved from www.kenaninstitute.unc.edu website: http://www.kenanflagler.unc.edu/ /media/files/kenaninstitute/UNC_KenanInstitute_2010Census

Kelley, S. J. (1993). Caregiver stress in grandparents raising grandchildren. Journal of Nursing Scholarship, 25(4), 331-337. doi: 10.1111/j.1547-5069.1993.tb00268.x

Kelley, S. J., Whitley, D., \& Sipe, T. A. (2007). Results of an interdisciplinary intervention to improve the psychosocial well-being and physical functioning of African American grandmothers raising grandchildren. Journal of Intergenerational Relationships, 5(3), 45-64.

Kelley, S. J., Whitley, D., Sipe, T. A., \& Yorker, B. C. (2000). Psychological distress in grandmother kinship care providers: The role of resources, social support, and physical health. Child Abuse \& Neglect, 24(3), 311-321. doi: 10.1016/s01452134(99)00146-5

Kelley, S. J., Whitley, D. M., \& Campos, P. E. (2010). Grandmothers raising grandchildren: Results of an intervention to improve health outcomes. Journal of Nursing Scholarship, 42(4), 379-386. doi: 10.1111/j.1547-5069.2010.01371.x

Kelley, S. J., Yorker, B. C., Whitley, D. M., \& Sipe, T. A. (2001). A multimodal intervention for grandparents raising grandchildren: results of an exploratory study. Child Welfare, 80(1), 27-50.

Kentucky State Data Center. (n. d.). County profiles from 2000 census data. Retrieved from http://ksdc.louisville.edu/1profiles_county.htm

King, I. M. (1990). Health as the goal for nursing. Nursing Science Quarterly, 3(3), 123128. doi: $10.1177 / 089431849000300307$

Kropf, N. P., \& Kolomer, S. (2004). Grandparents raising grandchildren: A diverse population. Journal of Human Behavior in the Social Environment, 9(4), 65-83. doi: 10.1300/J137v09n04_04 
Kropf, N. P., \& Robinson, M. M. (2004). Pathways into caregiving for rural custodial grandparents. Journal of Intergenerational Relationships, 2(1), 63-77. doi: 10.1300/J194v02n01_05

Larson, J. S. (1999). The conceptualization of health. Medical Care Research \& Review, 56(2), 123-136. doi: 10.1177/107755879905600201

Leder, S., Nicholson Grinstead, L., \& Torres, E. (2007). Grandparents raising grandchildren: Stressors, social support, and health outcomes. Journal of Family Nursing, 13(3), 333-352. doi: 10.1177/1074840707303841

Linsk, N., Mason, S., Fendrich, M., Bass, M., Prubhughate, P., \& Brown, A. (2009). "No matter what I do they still want their family": Stressors for African American grandparents and other relatives. Journal of Family Social Work, 12(1), 25-43.

Linsk, N. L., \& Mason, S. (2004). Stresses on grandparents and other relatives caring for children affected by HIV/AIDS. Health \& Social Work, 29(2), 127-136.

Maruish, M. E. (Ed.). (2011). User's manual for the SF-36v2® Health Survey (3rd ed.). Lincoln, RI: QualityMetric Incorporated.

McHorney, C. A., Ware, J. E., Jr., \& Raczek, A. E. (1993). The MOS 36-Item ShortForm Health Survey (SF-36): II. Psychometric and clinical tests of validity in measuring physical and mental health constructs. Medical Care, 31(3), 247-263.

Minkler, M., \& Fuller-Thomson, E. (1999). The health of grandparents raising grandchildren: Results of a national study. American Journal of Public Health, 89(9), 1384-1389. doi: 10.2105/ajph.89.9.1384

Minkler, M., Fuller-Thomson, E., Miller, D., \& Driver, D. (1997). Depression in grandparents raising grandchildren: Results of a national longitudinal study. Arch Fam Med, 6(5), 445-452. doi: 10.1001/archfami.1997.01850520051011

Minkler, M., Roe, K. M., \& Price, M. (1992). The physical and emotional health of grandmothers raising grandchildren in the crack cocaine epidemic. The Gerontologist, 32(6), 752-761.

Musil, C. (1998). Health, stress, coping, and social support in grandmother caregivers. Health Care for Women International, 19(5), 441-455.

Musil, C. (2000). Health of grandmothers as caregivers: A ten month follow-up. Journal of Women and Aging, 12(1-2), 129-145.

Musil, C. M., \& Ahmad, M. (2002). Health of grandmothers: A comparison by caregiver status. Journal of Aging and Health, 14(1), 96-121. doi:

$10.1177 / 089826430201400106$ 
Musil, C. M., Warner, C., Zauszniewski, J., Wykle, M., \& Standing, T. (2009). Grandmother caregiving, family stress and strain, and depressive symptoms. Western Journal of Nursing Research, 31(3), 389-408. doi: $10.1177 / 0193945908328262$

Musil, C. M., Youngblut, J. M., Ahn, S., \& Curry, V. L. (2002). Parenting stress: A comparison of grandmother caretakers and mothers. Journal of Mental Health and Aging, 8(3), 197-210.

Myers, L. L., Kropf, N. P., \& Robinson, M. (2002). Grandparents raising grandchildren: Case management in a rural setting. Journal of Human Behavior in the Social Environment, 5(1), 53.

Pearlin, L. I., Mullan, J. T., Semple, S. J., \& Skaff, M. M. (1990). Caregiving and the stress process: An overview of concepts and their measures. The Gerontologist, 30(5), 583-594.

Polit, D. F., \& Beck, C. T. (2008). Nursing research: Generating and assessing evidence for nursing practice (8th ed.). Philadelphia, PA: Wolters Kluwer/Lippincott Williams \& Wilkins.

Quality Metric Incoporated. (2009). Quick start guide for the SF-36v2 health survey. Retrieved from http://toolkit.techandaging.org/files/2011/03/SF-36-HealthSurvey-Quick-Start-Guide1.pdf

Racher, F. E., Vollman, A. R., \& Annis, R. C. (2004). Conceptualizations of "rural": Challenges and implications for nursing research. Online Journal of Rural Nursing \& Health Care, 4(2), 61-77. Retrieved from www.cinahl.com/cgi-

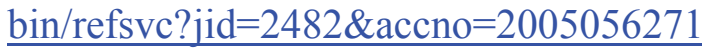

Radloff, L. S. (1977). The CES-D scale: A self-report depression scale for research in the general population. Applied Psychological Measurement, 1(3), 385-401. doi: $10.1177 / 014662167700100306$

Roe, K. M., Minkler, M., Saunders, F., \& Thomson, G. E. (1996). Health of grandmothers raising children of the crack cocaine epidemic. Med Care, 34(11), 1072-1084.

Ruiz, D. S., Zhu, C. W., \& Crowther, M. R. (2003). Not on their own again: Psychological, social, and health characteristics of custodial African American grandmothers. Journal Of Women \& Aging, 15(2-3), 167-184.

Saylor, C. (2004). The circle of health: A health definition model. Journal of Holistic Nursing, 22(2), 97-115. doi: 10.1177/0898010104264775 
Schwarzer, R., \& Schwarzer, C. (1996). A critical survey of coping instruments. In M. Zeidner \& N. S. Endler (Eds.), Handbook of Coping. New York: Wiley.

Shaw, C. (1999). A framework for the study of coping, illness behaviour and outcomes. Journal of Advanced Nursing, 29(5), 1246-1255.

Simmons, T., \& Dye, J. L. (2003). Grandparents living with grandchildren: 2000, census 2000 brief. Washington, D. C.

Son, J., Erno, A., Shea, D. G., Femia, E. E., Zarit, S. H., \& Parris Stephens, M. A. (2007). The caregiver stress process and health outcomes. Journal of Aging and Health, 19(6), 871-887. doi: 10.1177/0898264307308568

Spencer, K. (2010, January 21, 2010). Rural health disparities frequently asked questions. Retrieved from http://www.raconline.org/info_guides/disparities/faq.php\#supporting

Spencer, K., Cromartie, J., Hart, G., \& Hirsch, S. (2010, June 5, 2010). What is rural? Frequently asked questions. Retrieved from http://www.raconline.org/info_guides/ruraldef/ruraldeffaq.php\#where

Trail Ross, M. E., \& Aday, L. A. (2006). Stress and coping in African American grandparents who are raising their grandchildren. Journal of Family Issues, 27(7), 912-932. doi: 10.1177/0192513x06287167

U. S. Census Bureau. (2008, September 1, 2009). Facts for features: Grandparents day 2008: Sept 7. Retrieved from http://www.census.gov/PressRelease/www/releases/archives/facts_for_features_special_editions/012095.html

U. S. Census Bureau. (2010, August 16, 2010). State and county quick facts: Hopkinsville, Kentucky. Retrieved from http://quickfacts.census.gov/qfd/states/21/2137918.html

U. S. Census Bureau. (2012). State and county quick facts: Kentucky. Retrieved June 14, 2012 http://quickfacts.census.gov/qfd/states/21000.html

U. S. Census Bureau. (n.d.). Grandparents: 2010: American Community Survey 1-year estimates. American Fact Finder. Retrieved May 29, 2012 http://factfinder2.census.gov/faces/tableservices/jsf/pages/productview.xhtml?pid $=$ ACS 10 1YR S100\&prodType $=$ table

Vitaliano, P. P., Young, H. M., \& Zhang, J. (2004). Is caregiving a risk factor for illness? Current Directions in Psychological Science, 13(1), 13-16. doi: 10.1111/j.09637214.2004.01301004.x 
Waldrop, D. P., \& Weber, J. A. (2001). From grandparent to caregiver: The stress and satisfaction of raising grandchildren. Families in Society: The Journal of Contemporary Human Services, 82(5), 461-472. doi: 10.1606/1044-3894.165

Ware, J. E., Jr. (2000). SF-36 Health Survey update. Spine, 25(24), 3130-3139.

Ware, J. E., Jr., Kosinski, M., Bjorner, J. B., Turner-Bowker, D. M., Gandek, B., \& Maruish, M. E. (2008). SF-36v2 ${ }^{\circledR}$ Health Survey: Administration guide for clinical trial investigators. Lincoln, RI: QualityMetric Incorporated.

Ware, J. E., Jr., \& Sherbourne, C. D. (1992). The MOS 36-Item short-form health survey (SF-36): I. conceptual framework and item selection. Medical Care, 30(6), 473483.

Whitley, D. M., Kelley, S. J., \& Sipe, T. A. (2001). Grandmothers raising grandchildren: Are they at increased risk of health problems? Health \& Social Work, 26(2), $105-$ 114. 


\section{APPENDIX. GRANDPARENTS RAISING GRANDCHILDREN DEMOGRAPHIC QUESTIONNAIRE}

1. What is your age? in years

2. Grandparent gender: male female

3. Relative caregiver race: (circle one) African American Caucasian

4. Marital status: (circle one)

Married/living with a partner

Not married (separated, divorced, widowed, never married)

5. Employment status: (circle one)

$$
\text { Employed Not employed }
$$

6. How many years of school did you complete?

7. List any current medical problems:

8. What healthcare services do you have available in your area?

9. Do you currently have health insurance and what type? 
10. What is the age and gender of the grandchildren who are in your custody or who you are their primary caregiver? How long have they been living with you?

\begin{tabular}{|l|l|l|}
\hline Age & Gender & $\begin{array}{l}\text { Length of time they have been in your } \\
\text { custody. Indicate if the number is in } \\
\text { months or years }\end{array}$ \\
\hline & & \\
\hline & & \\
\hline & & \\
\hline & & \\
\hline & & \\
\hline
\end{tabular}

11. What is the reason that you have custody of your grandchildren?

12. Which of the following best describes the area you live in: (circle one)
Rural
Suburban
Urban/Metropolitan 


\section{VITA}

Kimberly Yvette Robitaille was born in Ardmore, Oklahoma in 1960. She received her Associate Degree in Nursing from Palomar Community College in San Marcos, California in 1988. She received her Bachelor of Science and Master of Science in Nursing from the University of Phoenix in Ontario, California in 1999 and 2000, respectively. She has over 28 years of experience as a nurse in a variety of settings. She has experience in multiple areas of nursing that include medical/surgical, home health, public health, oncology, intravenous therapy, and nursing education. She has also held various roles within these settings to include staff nurse, case manager, nursing supervisor, nurse manager, and nurse educator.

She has presented several poster presentations at annual Southern Nursing Research Society conferences since 2011. She recently co-authored a manuscript that has been accepted for publication in the Journal of Pediatric Oncology. She has also presented at one regional and one national conference. She has been a member of Sigma Theta Tau since 2000.

Kimberly Robitaille received a Doctor of Philosophy in nursing degree from the University of Tennessee Health Science Center in December 2012. Her dissertation research focused on the physical and mental health, stressors, coping, and social supports of rural grandparents raising grandchildren. Currently, she is an associate professor at Hopkinsville Community College in Hopkinsville, Kentucky. 